\title{
Pregnancy-Associated Plasma Protein-aa Regulates Photoreceptor Synaptic Development to Mediate Visually Guided Behavior
}

\author{
Andrew H. Miller, ${ }^{1,2}$ Hollis B. Howe, ${ }^{1}$ @Bryan M. Krause, ${ }^{3}$ Scott A. Friedle, ${ }^{1}{ }^{\circledR}$ Matthew I. Banks, ${ }^{3}$ @Brian D. Perkins, ${ }^{4}$ \\ and ${ }^{\circ}$ Marc A. Wolman ${ }^{1}$ \\ ${ }^{1}$ Department of Integrative Biology, ${ }^{2}$ Neuroscience Training Program, School of Medicine and Public Health, ${ }^{3}$ Department of Anesthesiology, School of \\ Medicine and Public Health, University of Wisconsin, Madison, Wisconsin 53706, and ${ }^{4}$ Department of Ophthalmic Research, Cole Eye Institute, Cleveland \\ Clinic, Cleveland, Ohio 44195
}

To guide behavior, sensory systems detect the onset and offset of stimuli and process these distinct inputs via parallel pathways. In the retina, this strategy is implemented by splitting neural signals for light onset and offset via synapses connecting photoreceptors to $\mathrm{ON}$ and OFF bipolar cells, respectively. It remains poorly understood which molecular cues establish the architecture of this synaptic configuration to split light-onset and light-offset signals. A mutant with reduced synapses between photoreceptors and one bipolar cell type, but not the other, could reveal a critical cue. From this approach, we report a novel synaptic role for pregnancy-associated plasma protein aa (рарраa) in promoting the structure and function of cone synapses that transmit light-offset information. Electrophysiological and behavioral analyses indicated pappaa mutant zebrafish have dysfunctional cone-to-OFF bipolar cell synapses and impaired responses to light offset, but intact cone-to-ON bipolar cell synapses and light-onset responses. Ultrastructural analyses of pappaa mutant cones showed a lack of presynaptic domains at synapses with OFF bipolar cells. pappaa is expressed postsynaptically to the cones during retinal synaptogenesis and encodes a secreted metalloprotease known to stimulate insulin-like growth factor 1 (IGF1) signaling. Induction of dominant-negative IGF1 receptor expression during synaptogenesis reduced light-offset responses. Conversely, stimulating IGF1 signaling at this time improved pappaa mutants' light-offset responses and cone presynaptic structures. Together, our results indicate Pappaaregulated IGF1 signaling as a novel pathway that establishes how cone synapses convey light-offset signals to guide behavior.

Key words: IGF1; Pappaa; photoreceptor; synapse; visual behavior; zebrafish

Significance Statement

Distinct sensory inputs, like stimulus onset and offset, are often split at distinct synapses into parallel circuits for processing. In the retina, photoreceptors and $\mathrm{ON}$ and $\mathrm{OFF}$ bipolar cells form discrete synapses to split neural signals coding light onset and offset, respectively. The molecular cues that establish this synaptic configuration to specifically convey light onset or offset remain unclear. Our work reveals a novel cue: pregnancy-associated plasma protein aa (pappaa), which regulates photoreceptor synaptic structure and function to specifically transmit light-offset information. Pappaa is a metalloprotease that stimulates local insulinlike growth factor 1 (IGF1) signaling. IGF1 promotes various aspects of synaptic development and function and is broadly expressed, thus requiring local regulators, like Pappaa, to govern its specificity.

\section{Introduction}

Sensory circuits are wired to translate information in the environment. Many sensory systems detect and code stimuli by their

Received Jan. 10, 2018; revised April 4, 2018; accepted April 30, 2018.

Author contributions: A.H.M., B.M.K., B.D.P., and M.A.W. designed research; A.H.M., H.B.H., B.M.K., S.A.F., B.D.P., and M.A.W. performed research; A.H.M., H.B.H., B.M.K., S.A.F., B.D.P., M.A.W., and M.I.B. analyzed data; A.H.M. and M.A.W. wrote the paper.

This work was supported by grants to A.H.M. [National Institutes of Health (NIH) Grant T32 GM007507], H.B.H. (University of Wisconsin Hilldale Undergraduate Research Award), M.I.B. (NIH Grant R01 GM116916), B.D.P. (NIH Grant R01 EY017037, the Doris and Jules Stein Professorship for Research to Prevent Blindness, and NIH Core Center Grant P30 EY025585), and M.A.W. (Greater Milwaukee Foundation Shaw Scientist Award 133-AAA2656). The authors thank Dr. Michael Taylor for technical advice on the electroretinograms; Drew Roenneburg (University of onset and offset. Neural signals conveying ON/OFF input are split into parallel circuits for processing (Chalasani et al., 2007b; Scholl et al., 2010; Gallio et al., 2011; Gjorgjieva et al., 2014). This split occurs at discrete circuit loci, such as the synapses between sensory neurons and interneurons (DeVries et al., 2006; Wes-

Wisconsin Department of Surgery Histology Core) and Ben August (University of Wisconsin Electron Microscopy Core) for technical assistance; and Dr. Cunming Duan for the hsp70:dn/GF1Ra-EGFP fish line.

The authors declare no competing financial interests.

Correspondence should be addressed to Marc Wolman, 213 Zoology Research Building, 1117 West Johnson Street, Madison, WI 53706. E-mail: mawolman@wisc.edu.

DOI:10.1523/JNEUROSCI.0061-18.2018

Copyright $\odot 2018$ the authors $\quad 0270-6474 / 18 / 385220-17 \$ 15.00 / 0$ 


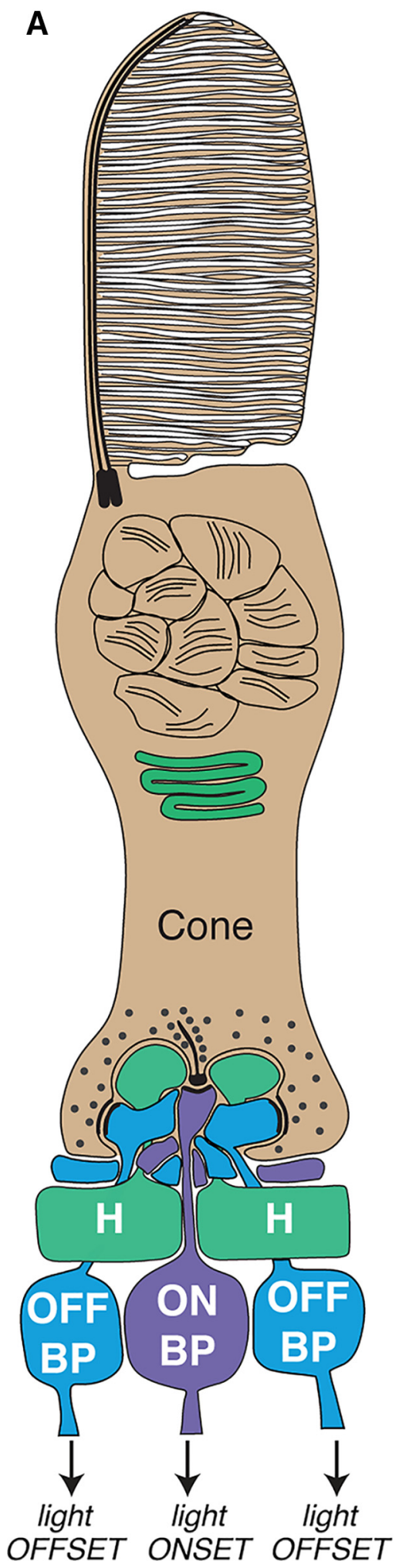

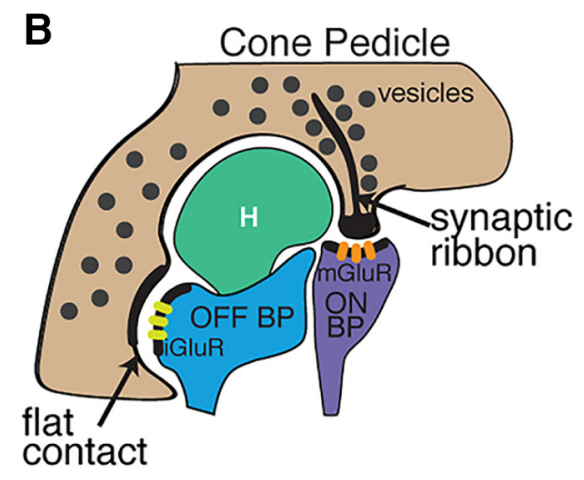

C Dark Flash: O-bend

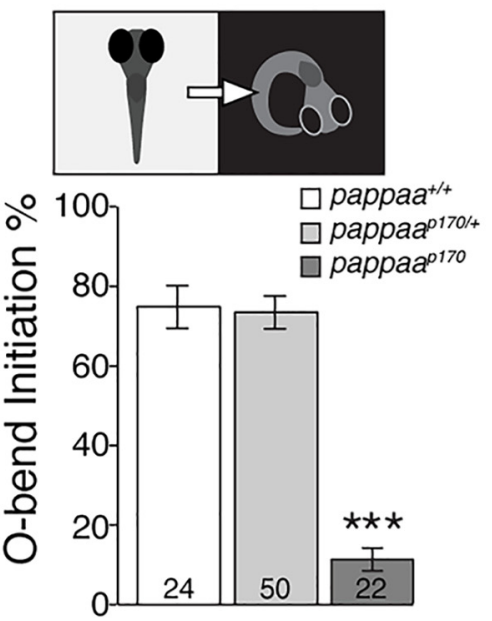

D Light flash: turn
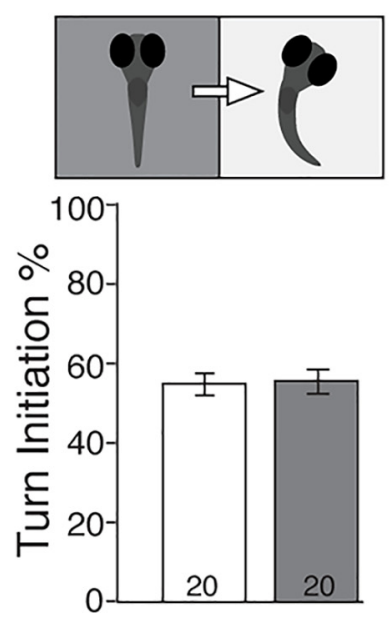

Figure 1. pappaa $^{p 170}$ larvae show impaired initiation of behaviors to light offset. $A$, Diagram of a cone photoreceptor and its synaptic connections with dendrites of ON (purple) and OFF bipolar cells (blue) and horizontal cells ( $\mathrm{H}$, green) within the retinal OPL. B, Higher-magnification view of contacts between cone and ON and OFF bipolar cells that indicates differences in synaptic structure. At cone-to-0N bipolar cell contacts, a synaptic ribbon is docked presynaptically and metabotropic glutamate receptors (mGluR) cluster at the postsynaptic density. At cone-to-OFF bipolar cell contacts, flat contacts are marked by presynaptic and postsynaptic densities and AMPA-type ionotropic glutamate receptors (iGluR) clusters postsynaptically. C, Dark flash stimulus elicits 0 -bend response. Mean frequency of 0 -bend responses initiated to a series of 10 dark flash stimuli. ${ }^{* *} p<0.001$, ANOVA with Bonferroni's correction. $\boldsymbol{D}$, Light flash elicits a low angle turn response. Mean frequency of turns initiated to a series of 10 light-flash stimuli. $N$ at base of bars, Number of larvae. Error bars indicate SEM.

theimer, 2007). Synapses epitomize the notion that form follows function, and thus their architecture mediating signal splitting must be established during development. For some circuits, the synapses that split ON/OFF signals have been identified and physiologically characterized (Wässle, 2004), yet the molecular cues that establish these synapses remain poorly understood. Defining these cues and their contribution to synaptic architecture will inform how synapses are built to split ON/OFF signals.

Visual circuits exemplify the splitting of ON/OFF stimuli. Retinal photoreceptor neurons respond to light onset and offset by modulating their release of glutamate, which differentially affects the activity of discrete postsynaptic bipolar cell populations (Wässle, 2004; Hoon et al., 2014). A cone photoreceptor's terminal establishes discrete synapses with invaginating dendrites of both $\mathrm{ON}$ and OFF bipolar cells to convey information about light onset and offset, respectively (Fig. 1 $A, B$ ). At the cone terminal's center, ON bipolar cell dendrites express metabotropic glutamate receptors and are flanked by horizontal cell dendrites (Haverkamp et al., 2000). Apposed to ON bipolar cell dendrites, the cone docks synaptic ribbons to mediate synaptic vesicle release (Schmitz, 2014). OFF bipolar cell dendrites invaginate peripheral regions of a cone's terminal and form "flat contacts" with the cone (Nelson and Connaughton, 1995). Flat contacts are identifiable by electron-rich presynaptic and postsynaptic densities (Dowling and Boycott, 1966). The postsynaptic domain includes clustered ionotropic, AMPAtype glutamate receptors on the OFF bipolar cell dendrites, whereas the presynaptic domain's composition remains unknown (Boycott and Hopkins, 1993; Tsukamoto and Omi, 2015).

Which molecular cues establish this synaptic configuration to specifically mediate the transmission of light onset or offset? A powerful tool to identify a cue is a mutant with dysfunctional synapses between photoreceptors and one bipolar cell type, but not the other. Zebrafish are ideal to isolate such a mutant, given the model's amenability to forward genetic screens for visual defects and their retinal circuits' rapid development and homology to mammals (Brockerhoff et al., 1995; Easter and Nicola, 1996; Neuhauss et al., 1999; Fadool and Dowling, 2008). By 5 d of age, cone-to-bipolar-cell synapses exhibit mature physiology and drive stereotyped behavioral responses to light onset and offset (Biehlmaier et al., 2003; 
Fleisch and Neuhauss, 2006; Burgess and Granato, 2007b; Burgess et al., 2010). Indeed, zebrafish mutants have revealed genes underlying the formation of photoreceptors' synapses to both bipolar cell types and of photoreceptors' synapses with ON bipolar cells (Brockerhoff et al., 1995; Neuhauss et al., 1999; Allwardt et al., 2001). These genes have been shown to regulate phototransduction, cell survival, vesicle recycling, calcium homeostasis, and cytoskeletal dynamics (Stearns et al., 2007; Lewis et al., 2011; Jia et al., 2014; Wasfy et al., 2014; Daniele et al., 2016; Lin et al., 2016; Shi et al., 2017). However, mutants have yet to reveal a cue that specifically promotes transmission of lightoffset signals by regulating the formation of synapses between photoreceptors and OFF bipolar cells. We identified a zebrafish mutant whose behavior, synaptic structure, and physiology makes it especially wellsuited to fill this void. These mutants harbor nonsense mutations in pregnancy-associated plasma protein aa (pappaa), which encodes a secreted metalloprotease that stimulates local insulin-like growth factor (IGF) signaling (Lawrence et al., 1999; Conover, 2012; Oxvig, 2015). The discovery of a role for Pappaa in synaptic development is novel. Here, we describe how Pappaa-IGF1R signaling influences cone-to-OFF bipolar cell synaptic structure and function and behavioral responses to light offset.

\section{Materials and Methods}

Fish maintenance and breeding. Larval zebrafish (Danio rerio) were raised from crosses of the following adults: Tubingen long-fin wild type; pappaa $^{\text {p170/+ }}$; $\mathrm{Tg}$ (isl2b-gfp); Tg(hsp70:dnIGF1Ra-EGFP); pappaa ${ }^{p 170 /+}$, $T g\left(\right.$ isl2b-gfp); or pappaa ${ }^{p 170 /+}, \mathrm{Tg}(h s p 70: d n I G F 1 R a-G F P)$. All lines were maintained on a Tubingen long-fin wild-type background. From fertilization, embryos and larvae were raised at $29^{\circ} \mathrm{C}$ in $\mathrm{E} 3$ medium $(5 \mathrm{~mm}$ $\mathrm{NaCl}, 0.17 \mathrm{~mm} \mathrm{KCl}, 0.33 \mathrm{~mm} \mathrm{CaCl}_{2}, 0.33 \mathrm{~mm} \mathrm{MgSO}_{4}, \mathrm{pH}$ adjusted to 6.8-6.9 with $\mathrm{NaHCO}_{3}$ ) on a 14:10 h light/dark cycle. To inhibit melanization, larvae used for fluorescent microscopy were raised in phenylthiourea ( $0.2 \mathrm{~mm}$ in $\mathrm{E} 3$ medium) in the dark beginning at $16-22 \mathrm{~h}$ postfertilization (hpf). All experiments were conducted between 4 and $10 \mathrm{~d}$ postfertilization (dpf). Larvae raised beyond $6 \mathrm{dpf}$ were fed paramecia. Genotyping of the pappaa ${ }^{p 170}$ allele was performed as previously described (Wolman et al., 2015).

Behavioral assays, video recording, and analysis. Behavioral responses to light-offset (dark flash), light-onset (light flash), and phototaxis stimuli were recorded using a MotionPro Y4 high-speed video camera (Integrated Design Tools) with a $50 \mathrm{~mm}$ macro lens (Sigma Corporation of America) at 1000 frames per second (unless otherwise noted) and $512 \times$ 512 pixel resolution. Larvae were illuminated from above with a mounted LED light (MCWHL5 $6500 \mathrm{~K}$ LED, powered by LEDD1B driver, Thorlabs) and below with an infrared light source (IR Illuminator CM-IR200B, C\&M Vision Technologies). Video images were analyzed for turn and swim initiations and kinematics with the Flote software package as previously described (Burgess and Granato, 2007a,b; Burgess et al., 2010; Wolman et al., 2011). On the day of testing, the $5 \mathrm{dpf}$ larvae were held in $60 \mathrm{~mm}$ Petri dishes with 20 larvae in $7 \mathrm{ml} \mathrm{E} 3$ and were adapted on a white light box $\left(800 \mu \mathrm{W} / \mathrm{cm}^{2}\right)$ for $\geq 1 \mathrm{~h}$ before testing as described below.

Light-offset-induced (dark flash) O-bends and light-onset-induced (light flash) turns were elicited and analyzed as previously described (Burgess and Granato, 2007b; Wolman et al., 2011). For data represented in Figure $3 D$, larvae were tested in $60 \mathrm{~mm}$ Petri dishes at the density indicated above. For data shown in Figure 12A, pappaa ${ }^{p 170}$ larvae were identified on $4 \mathrm{dpf}$ based on their failure to habituate to acoustic stimuli (Wolman et al., 2015) and then grouped in $60 \mathrm{~mm}$ Petri dishes with 20 larvae and $7 \mathrm{ml} \mathrm{E} 3$ in each dish for testing. For data shown in Figures $1 C, D$ and $3 C, E-I$, the larvae were transferred from Petri dishes to a $4 \times 4$ grid for testing, and then genotyped for pappaa ${ }^{p 170}$ post hoc (Wolman et al., 2011, 2015). In the dish or grid, larvae were acclimated to the illuminated testing stage $\left(85 \mu \mathrm{W} / \mathrm{cm}^{2}\right.$ for dark flashes, $25 \mu \mathrm{W} / \mathrm{cm}^{2}$ for light flashes) for $5 \mathrm{~min}$ before exposure to a series of 10 flash stimuli (dark flash, lights off; light flash, light increased to $600 \mu \mathrm{W} / \mathrm{cm}^{2}$ within $1 \mathrm{~ms}$ ).
Each stimulus lasted for $1 \mathrm{~s}$ and stimuli were presented at a $30 \mathrm{~s}$ interstimulus interval.

Phototaxis was performed as previously described (Burgess et al., 2010). pappaa ${ }^{p 170}$ larvae were identified at $4 \mathrm{dpf}$ based on their failure to habituate to acoustic stimuli (Wolman et al., 2015) and then grouped in $60 \mathrm{~mm}$ Petri dishes with 20 larvae and $7 \mathrm{ml} \mathrm{E} 3$ in each dish for testing. Each dish of larvae was acclimated to an illuminated testing stage (25 $\mu \mathrm{W} / \mathrm{cm}^{2}$ ) for $5 \mathrm{~min}$. To elicit phototaxis, the uniform illumination was removed, revealing a small target light $\left(10 \mu \mathrm{W} / \mathrm{cm}^{2}\right)$ on one side of the arena for $30 \mathrm{~s}$. Larvae initially positioned on the side (half) of the dish with the target light were excluded from analysis. Larvae oriented perpendicular to the target light $\left(75-105^{\circ}\right)$ were analyzed for turn directionality (Fig. $2 B$ ), and larvae facing the target light $\left(-30\right.$ to $\left.30^{\circ}\right)$ were analyzed for swims toward the target (Fig. 2C). Each dish was tested for phototaxis three times, with $5 \mathrm{~min}$ of uniform illumination $(25 \mu \mathrm{W} /$ $\mathrm{cm}^{2}$ ) between trials.

Optokinetic response (OKR) measurements were performed as previously described (Daniele et al., 2016; Lessieur et al., 2017). Larvae at $5 \mathrm{dpf}$ were assessed for contrast sensitivity using a VisioTracker system (VisioTracker 302060 Series, TSE Systems). A stimulus was presented for $3 \mathrm{~s}$ before reversing direction for another $3 \mathrm{~s}$. Stimuli were presented with a constant angular velocity of $7.5 \%$ s. Genotyping was performed post hoc.

RT-PCR and gel electrophoresis. Total RNA was extracted from $5 \mathrm{dpf}$ wild-type and pappaa ${ }^{p 170}$ larvae using TRIzol (Invitrogen). Wild-type and pappa $a^{p 170}$ mutant larvae were identified behaviorally by an acoustic startle habituation assay at $5 \mathrm{dpf}$ as previously described (Wolman et al., 2011, 2015). cDNA was synthesized using SuperScript II Reverse Transcriptase (Invitrogen). PCR amplification was performed for pappaa ( pappaa forward primer: A GAC AGG GAT GTG GAG TAC G, reverse primer: GTT GCA GAC GAC AGT ACA GC, 1005 bp amplicon spanning exons 11-17) and zebrafish $\beta$-actin (actb1 forward primer: TAC AGC TTC ACC ACC ACA GC; reverse primer: AAG GAA GGC TGG AAG AGA GC, 206 bp amplicon in exon 4; Wang et al., 2005). cDNA products were run alongside a $1 \mathrm{~kb}$ Plus DNA ladder (Invitrogen) on a $1 \%$ agarose gel.

Pharmacology. Larvae were treated with the following compounds by addition of the compound to the larvae's E3 media: SC-79 (Tocris Bioscience), recombinant IGF1 (Cell Sciences), and AMPA (Tocris Bioscience). SC-79 was dissolved in 100\% DMSO and administered in a final concentration in $1 \%$ DMSO in E3. IGF1 was dissolved in $10 \mathrm{~mm} \mathrm{HCl}$ to 1 $\mathrm{mg} / \mathrm{ml}$ and further diluted in E3 to be administered at a desired final concentration. AMPA was dissolved and administered in E3. Control treatments were either 1\% DMSO in E3 (for SC-79) or E3 only (for IGF1, AMPA). For treatments over multiple days, the compound/E3 was replaced every $12 \mathrm{~h}$. For acute treatments on $5 \mathrm{dpf}$, larvae were bathed in the compound/E3 for $20 \mathrm{~min}$ before and during the behavioral testing. Doses of each compound were prescreened for potential effects on embryonic and larval health, gross behavior, baseline startle responsiveness, and the stereotyped kinematic parameters of O-bend behavior (Burgess and Granato, 2007b).

Pappa and dominant-negative IGF1Ra misexpression. For human pappa RNA injection, full-length human pappa and $p a p p a^{E 483 A}$ constructs (Boldt et al., 2001) were transcribed using the mMessage mMachine kit (Ambion) and injected at the one-cell stage at doses ranging from 1 to $200 \mathrm{pg}$. Embryos injected with $>100 \mathrm{pg}$ pappa or pappa ${ }^{E 483 A}$ mRNA showed gross morphological abnormalities and necrosis, whereas embryos injected with $\leq 100$ pg pappa appeared morphologically normal. One hundred picogram injections were used to generate data in Figure 3C. pappa mRNA expression at $5 \mathrm{dpf}$ was validated as previously described (Wolman et al., 2015).

To induce expression of dominant-negative IGF1Ra-EGFP, we heatshocked $\operatorname{Tg}(h s p 70: d n I G F 1 R a-E G F P)$ larvae for $1 \mathrm{~h}$ every $12 \mathrm{~h}$ at $37^{\circ} \mathrm{C}$ (Kamei et al., 2011). Expression was verified by GFP fluorescence. Larvae heat-shocked on $5 \mathrm{dpf}$ were tested for behavior 3-6 h after heat shock. Induced expression of $d n I G F 1 R a-E G F P$ from 24 to $72 \mathrm{hpf}$ caused $10-$ $20 \%$ of the embryos to show mild morphological abnormalities. These embryos were removed and not tested for behavior. Onset of $d n I G F 1 R a-$ EGFP expression at $\geq 3 \mathrm{dpf}$ did not yield morphological defects.

Immunohistochemistry and in situ hybridization. For whole-mount immunostaining, larvae at $4-5 \mathrm{dpf}$ were fixed in $4 \%$ paraformaldehyde 
A

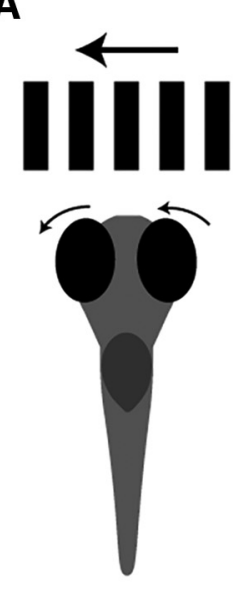

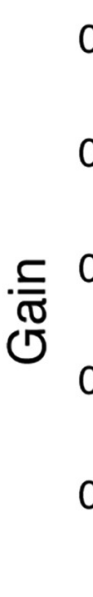

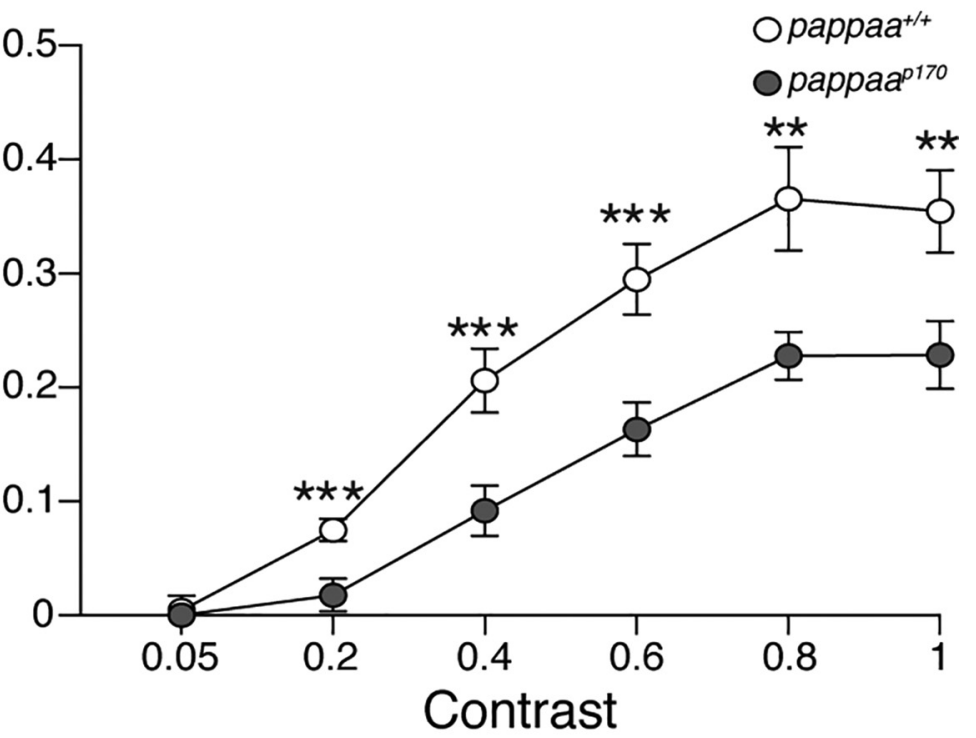

B Turn away from dark
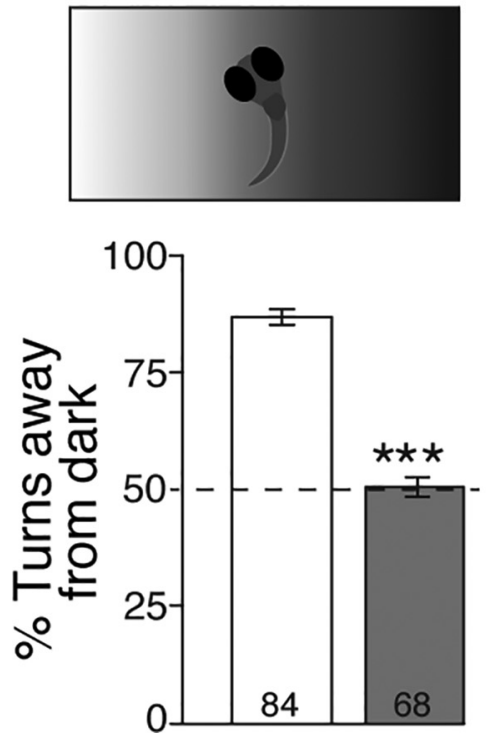

C Swim toward light

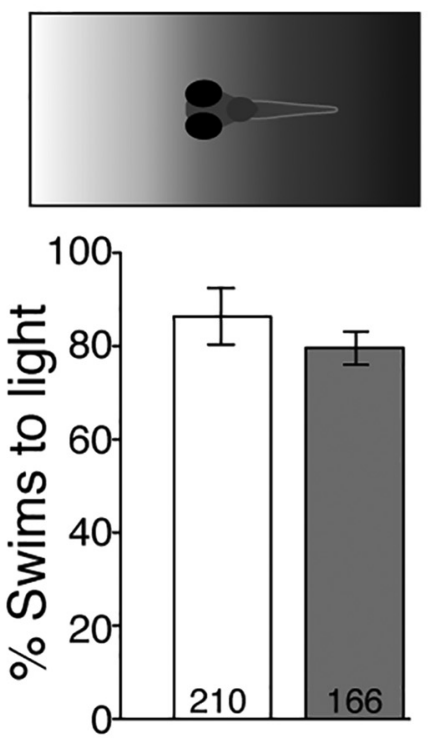

Figure 2. Contrast-mediated behavior by pappaa ${ }^{p 170}$ larvae. $A, 0 K R$ allows larval eyes to track movement of alternating bars of varying contrast. Mean OKR gain (eye velocity/stimulus velocity) at varying contrasts. $N=8$ larvae per genotype. ${ }^{* *} p<0.01,{ }^{* * *} p<0.001, T$ tests between genotypes at each contrast value. $B, C$, To perform phototaxis, larvae positioned perpendicular to a light gradient stereotypically turn away from darkness $(\boldsymbol{B})$ and once positioned toward the light, a larva will initiate swim bouts $(\boldsymbol{C})$. $\boldsymbol{B}$, Mean percentage of turns initiated away from darkness by larvae positioned between 75 and $105^{\circ}$ to the light- dark gradient. ${ }^{* * *} p<0.001, T$ tests between genotypes. C, Mean frequency of swim bouts initiated by larvae facing $\pm 30^{\circ}$ of the light $s$ timulus. N at base of bars, Number of trials in which a turn $(\boldsymbol{B})$ or swim $(\boldsymbol{C})$ was evaluated based on larval position with respect to target light. Error bars indicate SEM.

(diluted to $4 \% \mathrm{w} / \mathrm{v}$ in PBS from $16 \% \mathrm{w} / \mathrm{v}$ in $0.1 \mathrm{~m}$ phosphate buffer, $\mathrm{pH}$ 7.4) for $1 \mathrm{~h}$ at room temperature. Larvae were permeabilized in collagenase $(0.1 \% \mathrm{w} / \mathrm{v}$ in PBS) for $3-4 \mathrm{~h}$ and blocked for $1 \mathrm{~h}$ at room temperature in incubation buffer (IB; $0.2 \% \mathrm{w} / \mathrm{v}$ bovine serum albumin, $2 \% \mathrm{v} / \mathrm{v}$ normal goat serum, $0.8 \% \mathrm{v} / \mathrm{v}$ Triton-X, $1 \% \mathrm{v} / \mathrm{v}$ DMSO, in PBS, $\mathrm{pH} 7.4$ ). Larvae were incubated in primary antibodies (see below) in IB overnight at $4^{\circ} \mathrm{C}$. Larvae were incubated in fluorescently conjugated secondary antibodies in IB for 3-4 h at room temperature and kept covered to block exposure to light thereafter. To stain cell nuclei, larvae were incubated in DAPI $(0.1 \mathrm{mg} / \mathrm{ml}$ in PBST; Sigma-Aldrich) for $1 \mathrm{~h}$ after the secondary antibody was removed. After staining, larval heads were dissected and mounted in Vectashield (Vector Laboratories), while the tails were used to genotype for pappaa $a^{p 170}$. Images were acquired with an Olympus Fluoview confocal laser scanning microscope (FV1000) using Fluoview software (FV10-ASW 4.2). To determine relative fluorescent intensity, raw integrated densities were measured from regions of interest and back- ground in summation projections (10 focal planes spanning $4.6 \mu \mathrm{m}$ ) using ImageJ software (Schindelin et al., 2012). Regions of interest were drawn around the retinal inner plexiform layer (IPL), retinal outer plexiform layer (OPL), and tectum. Relative fluorescence was reported as the ratio to DAPI staining in adjacent cell layers in the photoreceptor layer, retinal ganglion cell layer, and tectum.

Primary antibodies included the following: red/green double-cone photoreceptors (anti-zpr-1, 1:100, mouse IgG1; Abcam), rod photoreceptors (anti-4c12, 1:100, mouse IgG; gift from Dr. Jim Fadool), ON bipolar cells (anti-PKC $\alpha, 1: 100$, rabbit IgG; Santa Cruz Biotechnology), amacrine cells (anti-5E11, 1:50, mouse IgG; gift from Dr. Jim Fadool), horizontal cells (anti-prox1, 1:100, mouse IgG; MilliporeSigma), bipolar and horizontal cells (anti-Lin7, 1:100, rabbit polyclonal serum; gift from Dr. Xiangyun Wei), Müller glia (anti-zrf-1, 1:500, mouse IgG1; Zebrafish International Resource Center), excitatory postsynaptic density (antipan-MAGUK clone K28/86, 1:100, mouse IgG1; University of California, 


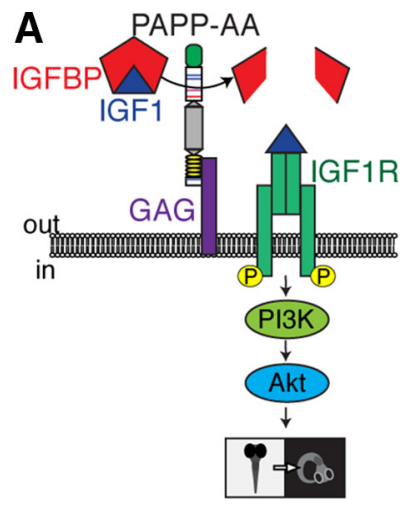

D

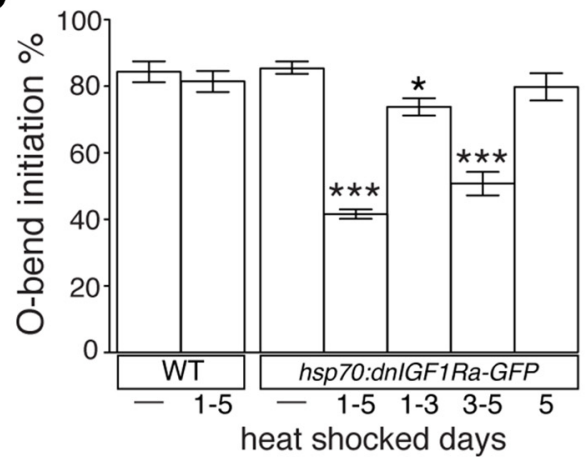

F

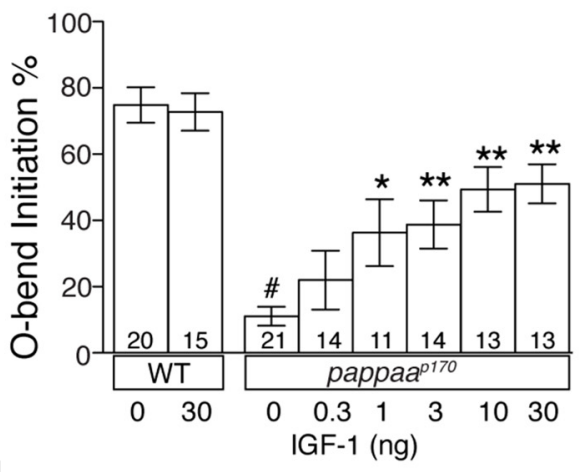

H

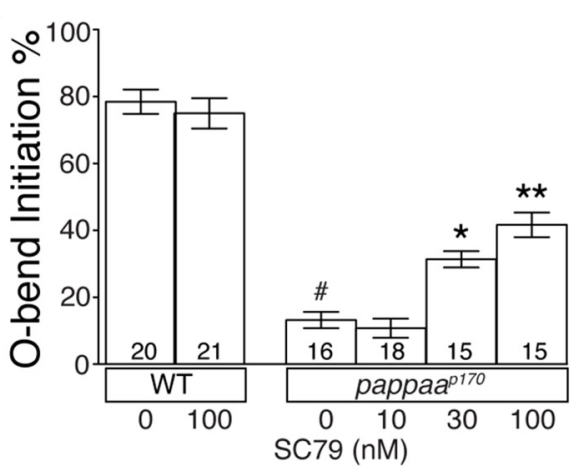

C

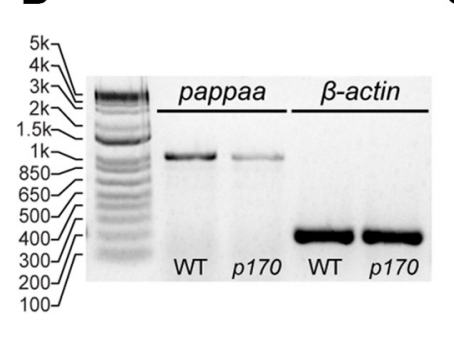

E

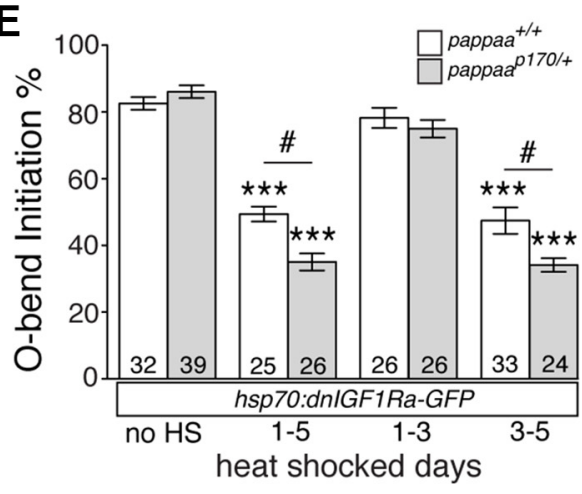

G

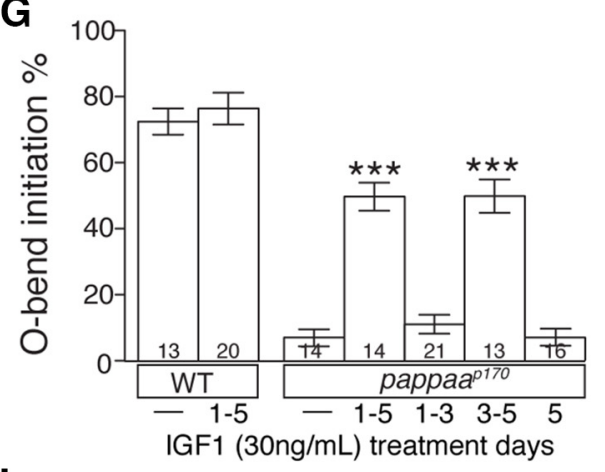

I

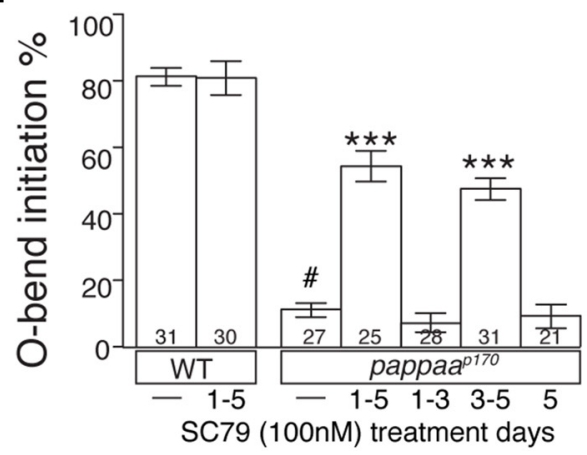

Figure 3. PAPPAA-IGF1R signaling promotes 0 -bend initiation to light offset. $\boldsymbol{A}$, Schematic of Pappaa-regulated IGF1 signaling. Pappaa is secreted, binds cell-surface glycosaminoglycan (GAG) and cleaves IGF binding proteins (IGFBP) to increase bioavailability of IGF1. "Free" IGF1 binds and activates the IGF1R, which stimulates PI3K and Akt to promote 0-bend initiation at light offset. $B$, RT-PCR indicates nonsense-mediated decay of pappaa ${ }^{\text {170 }}$ transcript. Gel bands reflect cDNA amplification of pappaa (1005 bp amplicon, exons 11-17) and $\beta$-actin (206 bp amplicon, exon 4) from 5 dpf wild-type or pappa $a^{p 170}$ larvae. C, Mean initiation frequency of 0 -bend responses at $5 \mathrm{dpf}$ after injection of human wild-type pappa $\mathrm{mRNA}$ or a proteolytically inactive $p a p p a{ }^{E 483 A} \mathrm{mRNA}{ }^{*{ }^{*}} p<$ 0.01 versus uninjected, ANOVA with Bonferroni's correction. $\boldsymbol{D}$-I, Mean initiation frequency of 0 -bend responses at $5 \mathrm{dpf}$ in the following conditions/experimental groups: (D) heat shock or no heat shock of wild-type or Tg(hsp70:dnIGF1Ra-GFP) larvae [ ${ }^{*} p<0.05$, ${ }^{* * *} p<0.001$ vs no heat shock Tg(hsp70:dnIGF1Ra-GFP) larvae, ANOVA with Bonferroni's correction; $N=5$ groups of 15 larvae per treatment condition]; (E) heat shock or no heat shock of Tg(hsp70:dn/GF1Ra-GFP) larvae in pappaa ${ }^{+/+}$or pappaa ${ }^{\text {p170/+ }}$ background $\left[^{* * *} p<0.001\right.$ vs no heat shock Tg(hsp70:dn/GF1Ra-GFP) of same genotype, ANOVA with Bonferroni's correction; $\# p<0.05, t$ test; N larvae shown at base of bars]; $(\boldsymbol{F}-\boldsymbol{I})$ treatment with recombinant IGF- $1(\boldsymbol{F}-\boldsymbol{G})$ or SC79 $(\boldsymbol{H}-\boldsymbol{I})$ from 3 to $5 \mathrm{dpf}(\boldsymbol{F}, \boldsymbol{H})$ or the days indicated $\left(\mathbf{G}, \mathbf{I} ; \# p<0.001\right.$ vs untreated wild type, ${ }^{*} p<0.05,{ }^{* *} p<0.01,{ }^{* * *} p<0.001$ vs untreated $p a p p a a^{p 170}$; ANOVA with Bonferroni's correction; $N$ larvae shown at base of bars; all error bars indicate SEM). 

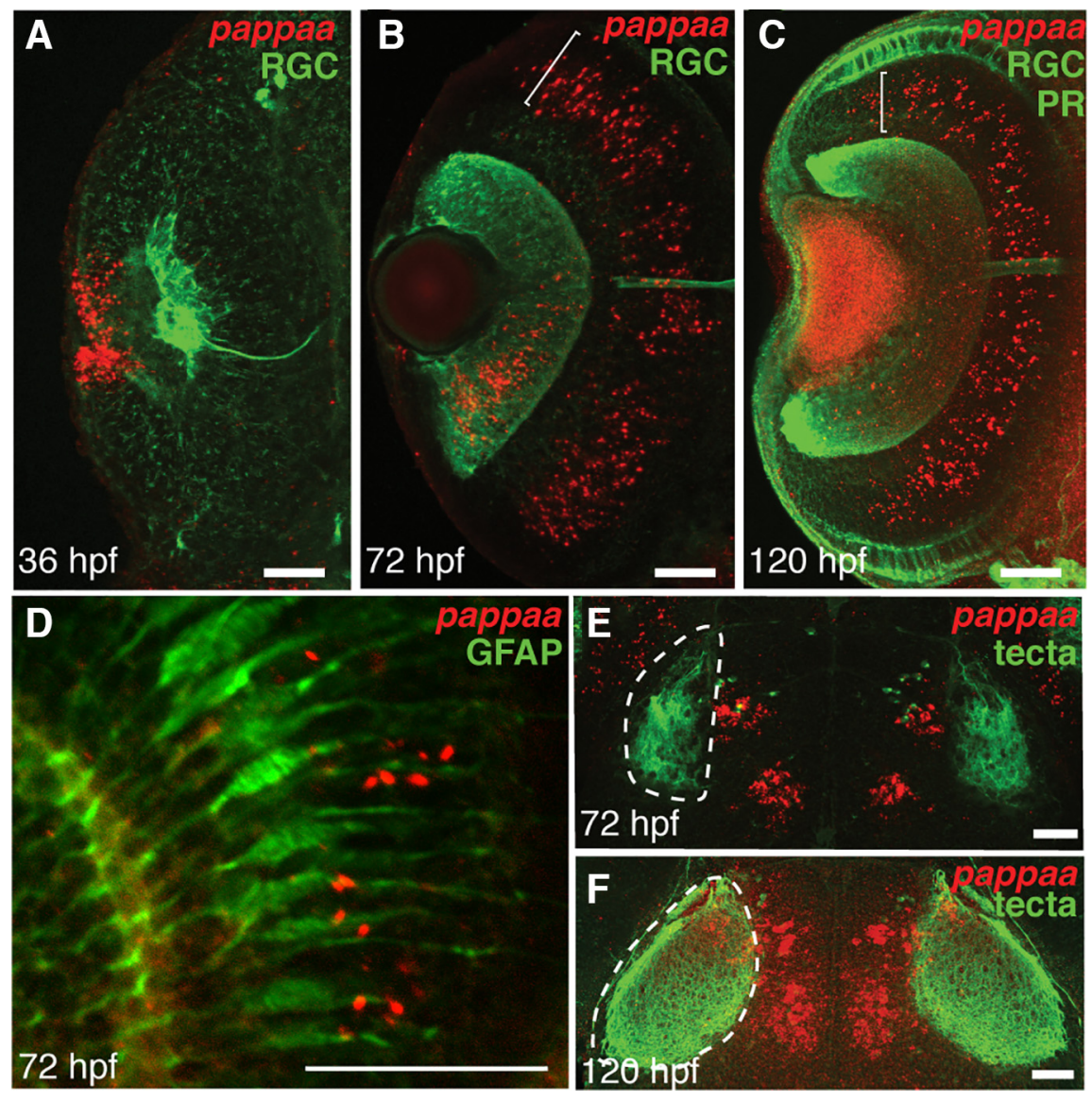

Figure 4. pappaa expression in the retina. $\boldsymbol{A}-\boldsymbol{C}$, In situ hybridization for pappaa mRNA (red) in the retina at $36(\boldsymbol{A}), 72(\boldsymbol{B})$, and $120 \mathrm{hpf}$ (C). $\operatorname{Tg}(\mathrm{I} / 2 \mathrm{~b}$ :GFP) (green) marks the retinal ganglion cells ( $\boldsymbol{A}-\boldsymbol{C}, \mathrm{RGC})$ and photoreceptors (C, PR). Brackets indicate retinal inner nuclear layer. D, pappaa mRNA (red) in the inner nuclear layer at $72 \mathrm{hpf}$ in combination with $\mathrm{Tg}$ (gfap:GFP) (green) marking Müller glia. $\boldsymbol{E}, \boldsymbol{F}$, pappaa mRNA (red) in the tectal region (dashed line marks tectal boundary) at 72 (E) and $120 \mathrm{hpf}(\boldsymbol{F}) . \mathrm{Tg}$ (Is/2b:GFP) (green) marks RGC axons' innervation of the tecta. All images are confocal projections of dorsal views, with anterior at the top of each panel. Labeling of lens in C is autofluorescence. Scale bar, $50 \mu \mathrm{m}$.

Davis/National Institutes of Health NeuroMab Facility), inhibitory postsynaptic density (anti-gephyrin, 1:100, mouse IgG1; Synaptic Systems), phosphorylated IGF1R (anti-IGF1 receptor phospho Y1161, 1:100, rabbit IgG; Abcam; Chablais and Jazwinska, 2010), AMPAR (anti-GluR4, 1:100, rabbit; MilliporeSigma), synaptic vesicle protein (anti-SV2, 1:100, mouse IgG1; Developmental Studies Hybridoma Bank), retinal ganglion cell projections and photoreceptors using larvae from $T g\left(\right.$ isl $2 b: G F P$ ); pappaa ${ }^{\text {p170/+ }}$ intercrosses (anti-GFP, 1:500, rabbit IgG; ThermoFisher Scientific), glia using larvae from $\mathrm{Tg}$ (gfap: GFP) crosses (anti-GFP, 1:250, rabbit IgG). Secondary antibodies included AlexaFluor488-conjugated and AlexaFluor594-conjugated secondary antibodies (goat anti-mouse IgG and IgG1, goat anti-rabbit IgG, 1:500; ThermoFisher Scientific).

Whole-mount in situ hybridization was performed on larva at 36, 72, and $120 \mathrm{hpf}$ as previously described (Halloran et al., 1999; Chalasani et al., 2007a) using digoxygenin-UTP-labeled antisense riboprobes for pappaa (Wolman et al., 2015). Images were acquired with an Olympus Fluoview confocal laser scanning microscope (FV1000) using Fluoview software (FV10-ASW 4.2).

Histology. For light microscopy, larvae at 5 and $10 \mathrm{dpf}$ were processed as previously described (Sullivan-Brown et al., 2011). Larvae were fixed in $4 \%$ paraformaldehyde (diluted to $4 \% \mathrm{w} / \mathrm{v}$ in PBS from $16 \% \mathrm{w} / \mathrm{v}$ in $0.1 \mathrm{M}$ phosphate buffer, $\mathrm{pH} 7.4$ ) overnight at $4^{\circ} \mathrm{C}$, dehydrated in a graded series of ethanol concentrations, and embedded in paraffin wax. Larvae were cut into 3- $\mu \mathrm{m}$-thick sections. Nuclei were stained with Harris hematoxylin and cytoplasm was stained with eosin Y. Images were acquired on a Nikon inverted light microscope (Eclipse TE300) using Spot software (v5.1, Diagnostic Instruments). Plexiform layer width and cell counts for each sample were measured from the histological section in which the lens was at its largest diameter. Plexiform layer width was averaged from six measurements each taken $10 \mu \mathrm{m}$ apart. Retinal cell bodies were counted across the entire section and averaged per area of the different retinal nuclear layers.

For electron microscopy (EM), larvae at $5 \mathrm{dpf}$ were processed as previously described (Allwardt et al., 2001). Larvae were fixed (1\% paraformaldehyde, $1.6 \%$ glutaraldehyde, 0.15 $\mathrm{mM} \mathrm{CaCl}_{2}$, and $3 \%$ sucrose in $0.06 \mathrm{M}$ phosphate buffer, $\mathrm{pH} 7.4$ ) for $15 \mathrm{~min}$ at $4^{\circ} \mathrm{C}$ and then rinsed and postfixed in osmium tetroxide $(2 \%$ in phosphate buffer) for $30 \mathrm{~min}$ at $4^{\circ} \mathrm{C}$ and $1.5 \mathrm{~h}$ at room temperature. The tissue was then rinsed in phosphate buffer and in maleate buffer $(0.05 \mathrm{M}, \mathrm{pH} 5.9)$ before being processed in a solution of $2 \%$ uranyl acetate in maleate buffer. The tissue was dehydrated in a graded series of ethanol concentrations, immersed into propylene oxide for $20 \mathrm{~min}$, infiltrated with Araldite/Epon resin, and cured for $72 \mathrm{~h}$ at $60^{\circ} \mathrm{C}$. Approximately 80 -nm-thick sections were mounted on slot grids and poststained with lead citrate and saturated uranyl acetate. Images were acquired on a Philips CM120 scanning transmission electron microscope with a BioSprint 12 series digital camera using AMT Image Capture Software Engine V700 (Advanced Microscopy Techniques). Image coloring to indicate cell type was added with Adobe Illustrator CC 2018 (Adobe Systems).

Electroretinogram. Electroretinography (ERG) was performed on larvae at 5-6 dpf. Experiments were performed at room temperature. Larvae were anesthetized in tricaine $(0.002 \%$ in E3; Sigma-Aldrich) for $1 \mathrm{~min}$ and then immobilized in low-melting-point agar (3\% with $0.002 \%$ tricaine in E3; Sigma-Aldrich) with one eye exposed. Larvae were placed in the recording chamber under a stimulus light (X-cite Exacte, Lumen Dynamics; light output adjusted to $90 \mu \mathrm{W} / \mathrm{cm}^{2}$ with neutral density filters). A glass electrode with a tip diameter between 20 and $40 \mu \mathrm{m}$ and filled with E3 medium was placed against the cornea. A reference electrode was inserted into the agar. Larvae were allowed to acclimate for $\geq 3 \mathrm{~min}$ before stimuli presentation. Larvae were presented with 20 light-offset stimuli (dark flashes) lasting $1 \mathrm{~s}$ with a $10 \mathrm{~s}$ interstimulus interval. Reported traces were averaged from the 20 stimuli and graphed with Matlab software (R2017a, Mathworks). The voltage signal was amplified (2000× gain; MultiClamp-700A, Molecular Devices), bandpass filtered (0.1 $\mathrm{Hz}-1 \mathrm{KHz}$ ), and digitized (40 kHz; Digidata 1322A, Molecular Devices). Wild-type and pappaa ${ }^{p 170}$ mutant larvae were identified behaviorally by an acoustic startle habituation assay at $4 \mathrm{dpf}$ as previously described (Wolman et al., 2011, 2015).

Statistics. Statistical analyses, including calculation of means, SE, and ANOVA were performed using Excel (Microsoft) and Prism software (GraphPad Software).

\section{Results}

\section{pappaa mutants show impaired initiation of behaviors to light offset}

By $5 \mathrm{dpf}$, larval zebrafish perform a repertoire of stereotyped motor behaviors in response to changes in visual field illumination (Neuhauss, 2003; Burgess and Granato, 2007b; Portugues and Engert, 2009; Burgess et al., 2010). For example, after light adaptation, 

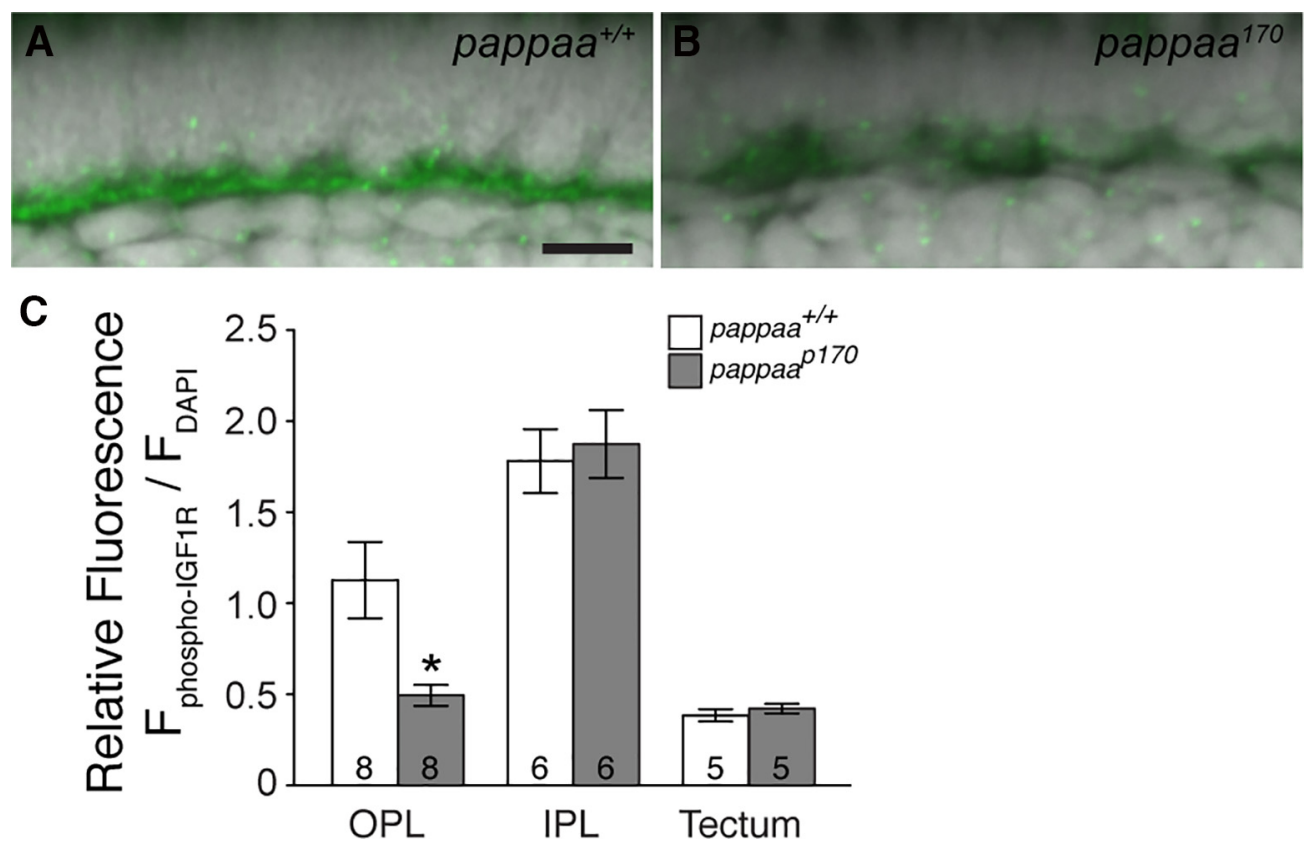

Figure 5. Phosphorylated IGF1R immunolabeling of the OPL. $A, B$, Summation intensity projections of anti-phosphorylated IGF1R immunolabeling of the OPL in wild-type (A) and pappaa ${ }^{p 170}$ larvae (B) at $5 \mathrm{dpf}$. Scale bar, $5 \mu \mathrm{m}$. C, Ratio of mean fluorescent intensity of anti-phosphorylated IGF1R to mean fluorescent intensity of DAPI-labeled photoreceptors for OPL, inner nuclear layer cells for INL, or tectal neurons (tecta). ${ }^{*} p<0.05 t$ test versus wild type. $N$, Number of larvae shown at base of bars. Error bars indicate SEM.

exposure to the sudden absence of light, termed a "dark flash," elicits an O-bend response in which larvae perform a large angle turn and reorient their body position by $\sim 180^{\circ}$ (Burgess and Granato, 2007b). To determine whether Pappaa activity is required for larvae to perform this response, we exposed pappaa $a^{p 170}$ larvae to 10 dark flashes and examined the initiation and performance of their O-bends. pappaa ${ }^{p 170}$ larvae showed a marked reduction in O-bend initiation compared with wild-type and pappaa $^{\text {p170/+ }}$ larvae (Fig. 1C). When pappaa ${ }^{p 170}$ larvae initiated an O-bend ( $n=25$ O-bends), their mean latency to initiate the O-bend [pappaa ${ }^{p 170}: 244.4 \pm 10.85 \mathrm{~ms}$ (mean $\pm \mathrm{SEM}$ ); pappaa $^{+/+}: 238.7 \pm 6.34 \mathrm{~ms}, p=0.74, t$ test], the mean body curvature of their O-bends (pappaa ${ }^{p 170}: 173.2 \pm 4.68^{\circ}$; pappaa $^{+/+}: 169 \pm$ $1.45^{\circ}, p=0.33, t$ test $)$, and their mean distance moved as a result of O-bending (pappaa ${ }^{p 170}: 7.70 \pm 0.63 \mathrm{~mm}$; pappaa $^{+/+}: 7.94 \pm 0.22$ $\mathrm{mm}, p=0.69, t$ test) were indistinguishable from O-bends performed by wild-type larvae ( $n=166$ O-bends). These results and prior characterization of the pappaa ${ }^{p 170}$ mutants (Wolman et al., 2015 ) suggest motor dysfunction does not underlie the pappaa $a^{p 170}$ mutants' reduced O-bend response initiation. Given the pappaa $a^{p 170}$ larvae's impaired responsiveness to light offset, we next asked whether Pappaa activity is also required for motor response initiation to sudden light onset. To address this, larvae were adapted to a dimly illuminated arena and then exposed to a sudden increase in illumination (a "light flash"), which elicits a low angle turn response (Burgess and Granato, 2007b). Wild-type and pappaa ${ }^{p 170}$ larvae showed a similar response frequency to the series of light flashes (Fig. $1 D)$. Together, these results indicate that Pappaa is required for larvae to respond to light offset, but not to light onset.

A distinction between light and dark underlies contrast perception, which zebrafish larvae use for navigation (Burgess et al., 2010). Given the pappaa ${ }^{p 170}$ larvae's impaired response initiation to light offset, we hypothesized that the mutants had defective contrast perception. To test this hypothesis, we performed an OKR assay, which measures eye tracking of rotating stripes that vary in contrast (Brockerhoff et al., 1995; Emran et al., 2008). At bars ranging in contrast from 0.2 to 1, pappaa $^{p 170}$ larvae, compared with wild-type larvae, showed a reduced ability to track the moving bars (Fig. 2A). To evaluate whether contrast-mediated navigation was also affected in the pappaa ${ }^{p 170}$ larvae, we performed a phototaxis assay. Larvae were first adapted to the uniformly illuminated arena and then presented with a small target light on one side of the arena, which was now otherwise darkened (Burgess et al., 2010). Under these conditions, wild-type larvae stereotypically initiate a turn away from the darkened side of the dish and then initiate swim bouts toward the target light (Burgess et al., 2010). Indeed, wild-type larvae positioned perpendicular to the luminance gradient initiated a turn away from the darker side of the gradient (Fig. $2 B$ ). When similarly positioned, pappaa ${ }^{p 170}$ larvae showed no directional bias in their turns, indicating a failure to turn away from darkness (Fig. 2B). However, when the pappaa $^{\text {p170 }}$ larvae faced the target light, they initiated swim bouts toward the light in a manner similar to that of wild-type larvae (Fig. 2C). Together, these results suggest that Pappaa mediates the detection of light offset, which underlies contrast-dependent visually guided behavior.

\section{Pappaa acts via IGF1R signaling to promote behavioral responses to light offset}

The discovery of a role for Pappaa in detecting illumination change and mediating visually guided behavior is novel. Therefore, we sought to characterize the molecular pathway by which Pappaa promotes behavioral responses to light offset. The mutation in pappaa ${ }^{p 170}$ truncates Pappaa upstream of its proteolytic domain (Wolman et al., 2015). For transcripts that harbor a premature termination codon, nonsense-mediated decay is a qualitycontrol mechanism that degrades targeted mRNA during translation and typically results in 2-20-fold downregulation (Gudikote et al., 2005; Pereverzev et al., 2015). Therefore, we evaluated pappaa expression by RT-PCR using primers that amplify a region of pappaa cDNA $3^{\prime}$ to the p170 mutation. We observed reduced pappaa product in pappaa ${ }^{p 170}$ mutants consistent with nonsense- 

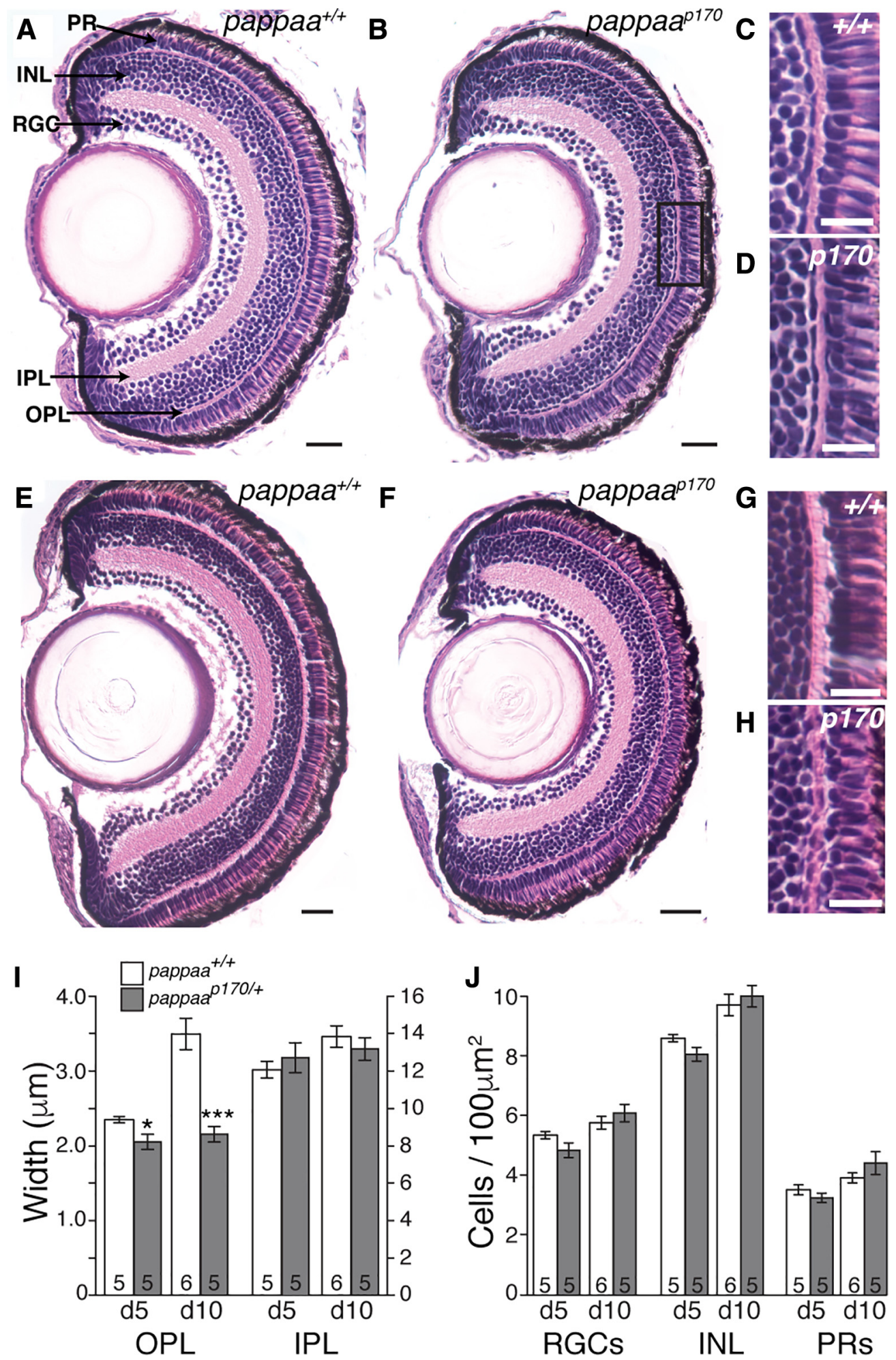

Figure 6. Cytoarchitecture of pappap ${ }^{p 170}$ retina. $\boldsymbol{A}-\boldsymbol{H}$, Histological sections of retinas at $5(\boldsymbol{A}-\boldsymbol{D})$ and $10 \mathrm{dpf}(\boldsymbol{E}-\boldsymbol{H})$ retinas of wild-type and pappaa ${ }^{\text {p170 }}$ larvae, stained with $\mathrm{H} \& \mathrm{E}$. Scale bars: $A, \boldsymbol{B}, \boldsymbol{E}, \boldsymbol{F}, 20 \mu \mathrm{m} ; \boldsymbol{C}, \boldsymbol{D}, \boldsymbol{G}, \boldsymbol{H}, 10 \mu \mathrm{m}$. I, Mean width of OPL and IPL. J, Mean counts of cells in retinal ganglion cell layer (RGC), INL, and photoreceptor layer (PR). N, Number of larvae shown at base of bars. ${ }^{*} p<0.05,{ }^{* * *} p<0.001$ versus wild type at same stage, Students $t$ test. Error bars indicate SEM.

mediated decay. Pappaa is a secreted metalloprotease that cleaves IGF binding proteins (IGFBPs) and therefore increases local IGF availability and activation of IGF receptors (Fig. $3 A$; Lawrence et al., 1999; Conover, 2012; Oxvig, 2015). We asked whether Pappaa's canonical proteolytic activity toward IGFBPs is required for behavioral responses to light offset. To address this, we tested whether an isoform of human PAPPA lacking protease activity ( $h$-pappa $a^{E 483 A}$ ) could improve the initiation of O-bend responses in pappaa ${ }^{p 170}$ larvae (Boldt et al., 2001). Control injections of $h$-pappa mRNA into one-cell stage embryos significantly increased O-bend initiation by pappaa ${ }^{p 170}$ larvae (Fig. 3C). However, injections of equimolar amounts of $h$-pappa ${ }^{E 483 A}$ mRNA 

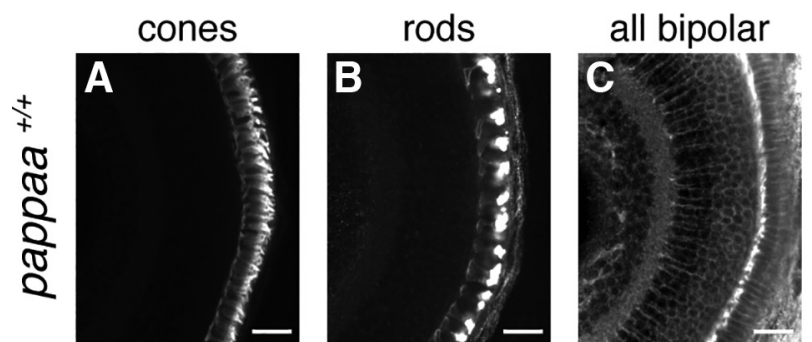

ON bipolar
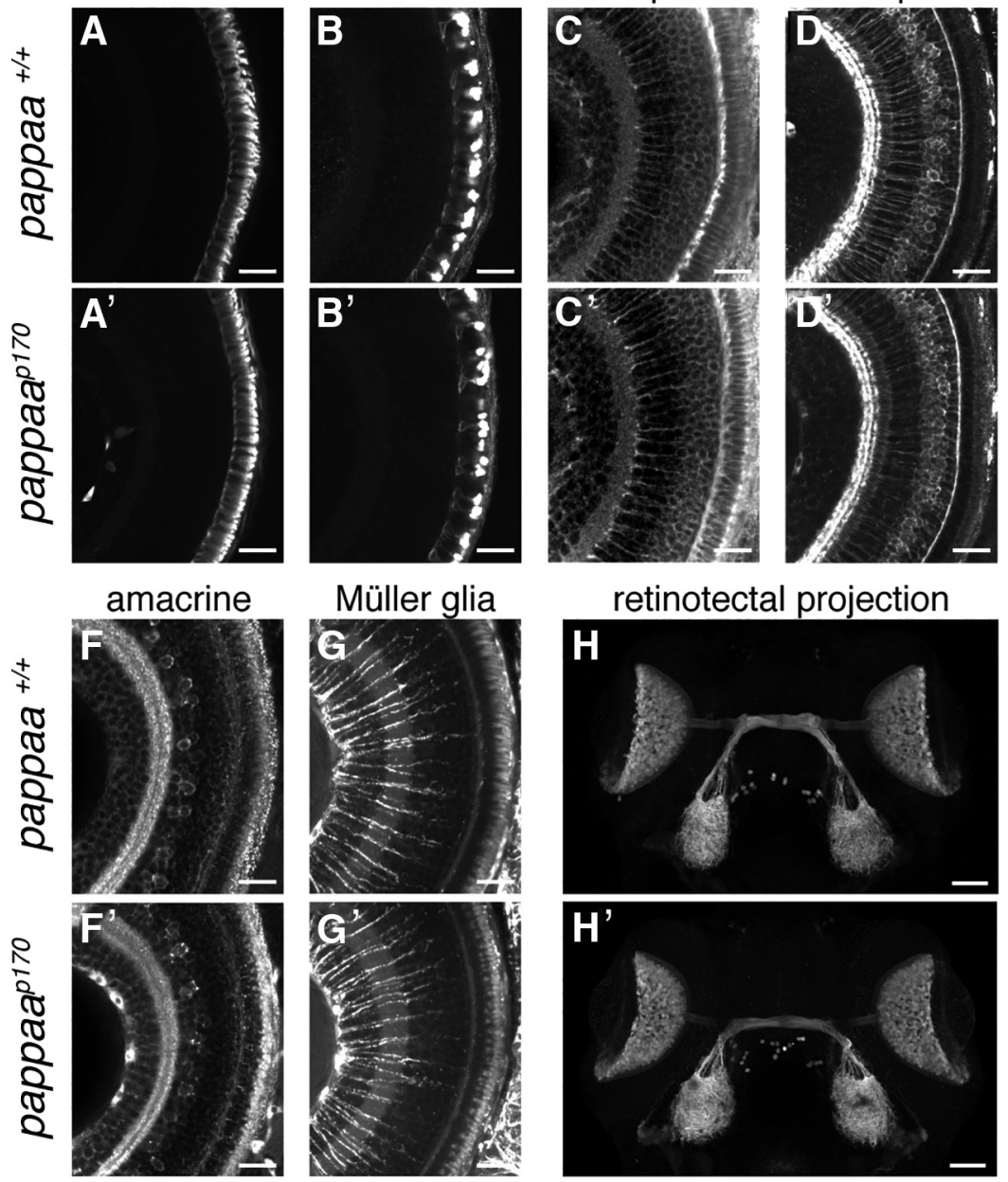

Müller glia

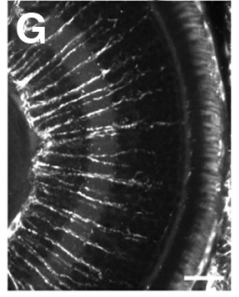

retinotectal projection
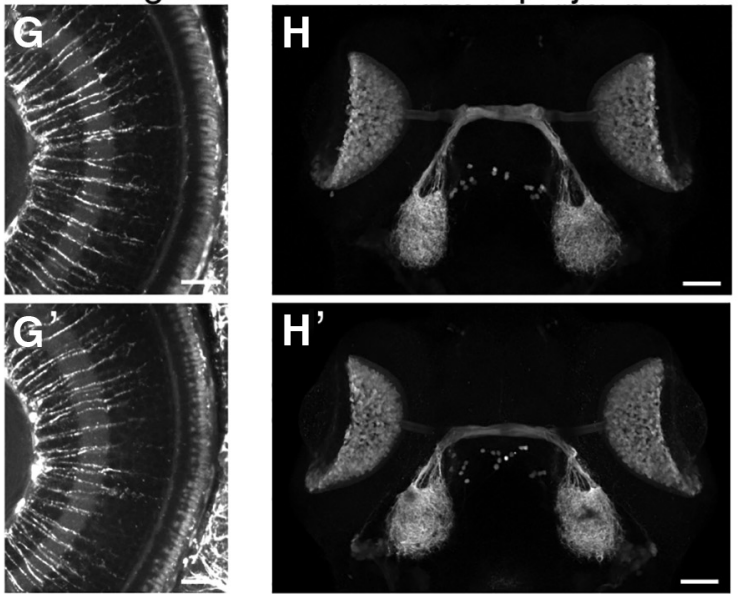

horizontal
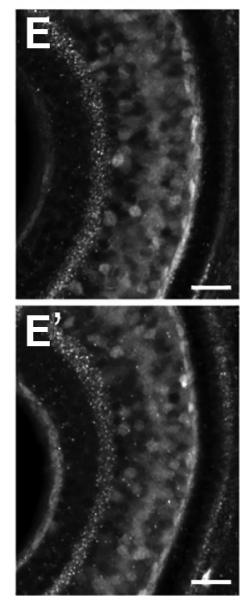

tectum
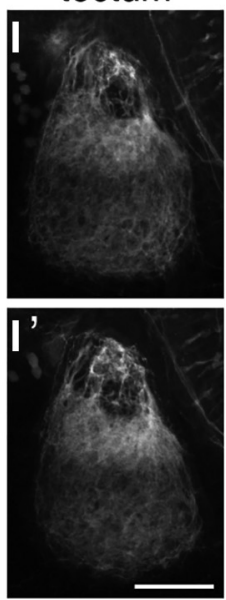

Figure 7. Retinal cell types and retinotectal projection of pappaa ${ }^{p 170}$ larvae. All images are maximal confocal projections (unless otherwise noted) of dorsal views, anterior at the top. A-G', Whole-mount immunolabeling of wild-type and pappaa ${ }^{\text {p170 }}$ larvae retinas for cone photoreceptors (zpr-1), rod photoreceptors (4c12), bipolar cells (Lin7), 0N bipolar cells (PKC $\alpha$ ), horizontal

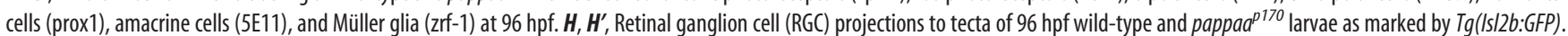
$\boldsymbol{I}, \boldsymbol{I}^{\prime}$, Representative summation projections of RGC axonal innervation of tecta at $96 \mathrm{hpf}$ in wild-type and pappaa ${ }^{\text {p170 }}$ larvae. RGC axons marked by $\mathrm{Tg}(\mathrm{ISI} / 2 \mathrm{~b}: \mathrm{GFP})$. Scale bars: $\boldsymbol{A}-\boldsymbol{G}^{\prime}, 20 \mu \mathrm{m}$; $\boldsymbol{H}-\boldsymbol{I}^{\prime}, 50 \mu \mathrm{m}$.

into pappaa ${ }^{p 170}$ did not improve their initiation of O-bends. These results indicate that Pappaa's metalloprotease activity is required for initiating responses to light offset.

We next asked whether Pappaa acts via IGF1R signaling to promote light-offset responses. We hypothesized that if Pappaa acts via IGF1R signaling, then attenuating IGF1R activity would reduce $\mathrm{O}$-bend response initiation. To test this hypothesis, we used a $T g(h s p 70: d n I G F 1 R a-G F P)$ transgenic line, in which a heat shock induces ubiquitous expression of dominant-negative IGF1Ra for $\sim 12 \mathrm{~h}$ (Kamei et al., 2011). Tg(hsp70:dnIGF1Ra-GFP) larvae heat-shocked once every $12 \mathrm{~h}$ from 1 to $5 \mathrm{dpf}$ showed reduced initiation of O-bends (Fig. 3D). This reduction by $\operatorname{Tg}(h s p 70$ : dnIGF1Ra-GFP) expression was stronger in the pappaa ${ }^{170 /+}$ background (Fig. $3 E$ ), suggesting a genetic interaction between pappaa and igflra. As controls, nontransgenic larvae were similarly heat-shocked and $\operatorname{Tg}(h s p 70: d n I G F 1 R a-G F P)$ larvae were not subjected to heat shock. Both groups exhibited normal O-bend responsiveness (Fig. $3 D, E$ ). Next, we hypothesized that if Pappaa acts via IGF1R signaling, then stimulating either IGF1 availability or a downstream effector of the IGF1R would improve O-bend responsiveness in pappaa ${ }^{p 170}$ larvae. To test this hypothesis, we bathed wild-type and pappaa ${ }^{p 170}$ larvae in recombinant human IGF1 protein or a small molecule activator of Akt (SC79), a canonical downstream effector of IGF1R signaling (Laviola et al., 2007; Jo et al., 2012). These treatments from 1 to $5 \mathrm{dpf}$ improved O-bend responsiveness in pappaa ${ }^{p 170}$ larvae in a dosedependent manner (Fig. $3 F-H$ ). Together, these results suggest that Pappaa acts via IGF1R signaling to promote a behavioral response to light offset.

We then addressed when Pappaa-dependent IGF1R signaling was required to promote O-bend response initiation. First, we hypothesized that the minimal period of $\operatorname{Tg}(h s p 70: d n I G F 1 R a-G F P)$ expression required to reduce $\mathrm{O}$-bend responsiveness would define the interval of IGF1R signaling that mediates O-bend initiation. Induction of $d n I G F 1 R a-G F P$ expression that was restricted to $1-3 \mathrm{dpf}$ or only at $5 \mathrm{dpf}$ was insufficient to strongly reduce O-bend initiation (Fig. $3 D, E$ ). Rather, we found that $d n I G F 1 R a-G F P$ expression from 3 to $5 \mathrm{dpf}$ reduced $\mathrm{O}$-bend initiation to a degree that most closely resembled the O-bend reduction caused by continuous dnIGF1Ra-GFP expression from 1 to $5 \mathrm{dpf}$ (Fig. $3 D, E$ ). Next, we hypothesized that the minimal period of IGF1 or SC79 exposure sufficient to improve O-bend responsiveness in pappaa ${ }^{p 170}$ larvae would define the critical period of Pappaa-IGF1R-Akt signaling. pappaa $^{\text {p170 }}$ larvae exposed to IGF1 or SC79 only from 1 to $3 \mathrm{dpf}$ or not until $5 \mathrm{dpf}$ failed to improve their O-bend initiation (Fig. $3 G, I)$. In contrast, IGF1 or SC79 treatments between 3 and $5 \mathrm{dpf}$ 

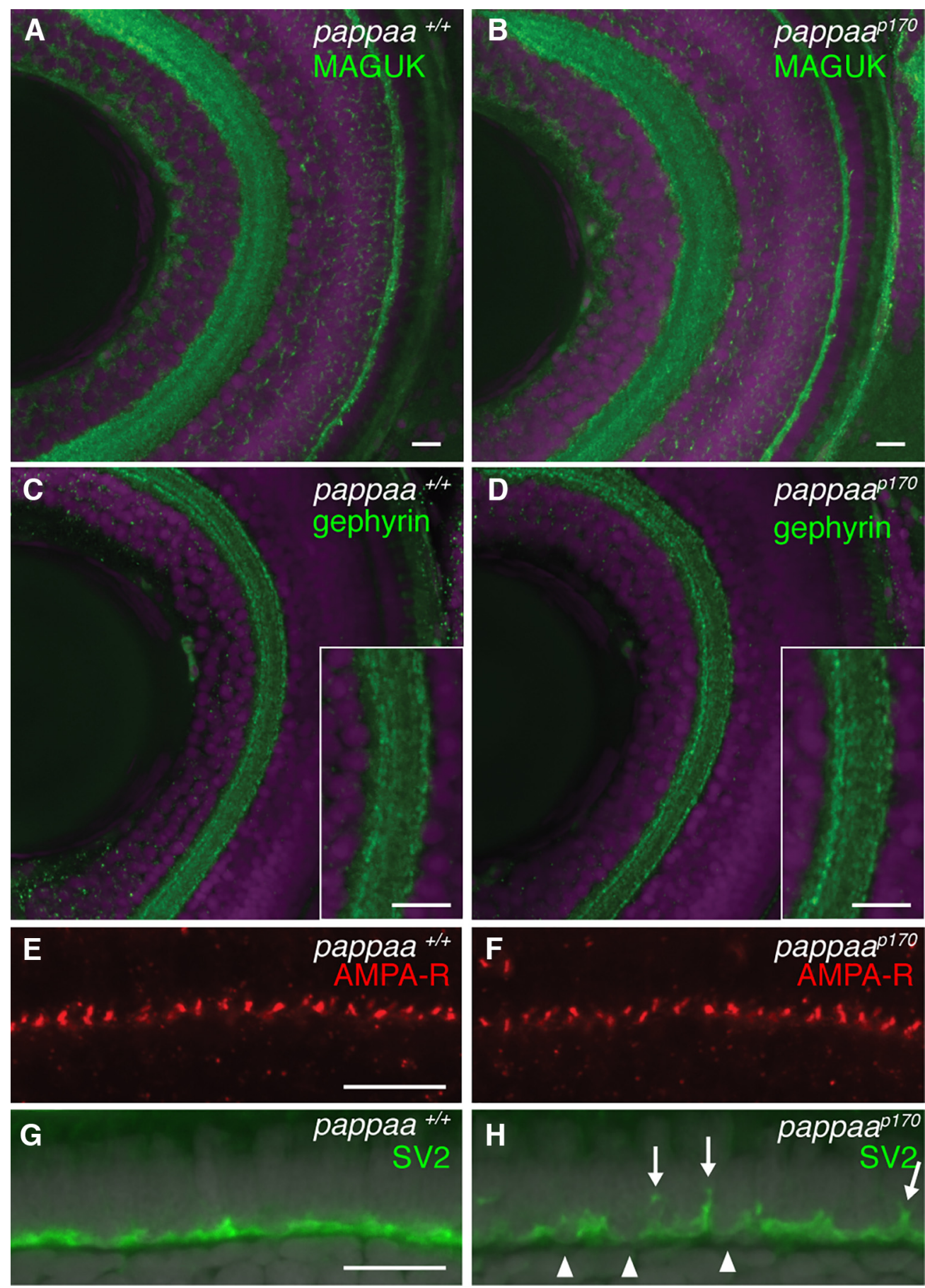

Figure 8. Retinal synaptic markers. $\boldsymbol{A}-\boldsymbol{D}$, Dorsal views, anterior at the top, of $5 \mathrm{dpf}$ wild-type and pappaa ${ }^{\text {p170 }}$ retinas labeled with anti-MAGUK $(\boldsymbol{A}, \boldsymbol{B})$ or anti-gephyrin antibodies $(\boldsymbol{C}, \boldsymbol{D})$ to mark excitatory and inhibitory postsynaptic densities, respectively. Cells (magenta) counterstained with DAPI. Insets in Cand $\boldsymbol{D}$ show lamination of IPL. $\boldsymbol{E}, \boldsymbol{F}$, AMPARs on OFF bipolar cell dendrites labeled by anti-GluR4 antibody. G, H, Synaptic vesicles in photoreceptors labeled by anti-SV2 antibody. Arrowheads mark gaps in anti-SV2 labeling rarely observed in wild type. Arrows mark anti-SV2 labeling that extended more proximally within the photoreceptor layer than observed in wild type. Cells (gray) counterstained with DAPI. Scale bars, $10 \mu \mathrm{m}$.

significantly increased pappaa ${ }^{p 170}$ larvae's O-bend responses (Fig. $3 G, I)$. Together, these results suggest that Pappaa-IGF1R-Akt signaling acts from 3 to $5 \mathrm{dpf}$ to promote a larvae's response to light offset.

pappaa is expressed in the retinal inner nuclear layer

The behavioral analyses of the pappaa ${ }^{p 170}$ larvae suggest that pappaa activity mediates the detection and interpretation of light offset, which occurs in the larvae's retina and its projection tar- gets. In mammals, retinal expression of PAPPA has been reported (Kay et al., 2012), but not described in temporal or spatial detail. We analyzed pappaa mRNA expression by whole-mount in situ hybridization from 36 to $120 \mathrm{hpf}$ in both the retina and its primary projection area: the optic tecta. This period encompasses the time when retinal and tectal neurons differentiate, form synapses, and establish the circuits that are sufficient to drive visually guided behaviors in $5 \mathrm{dpf}$ larvae. We observed transient pappaa expression in the ventral retina at $36 \mathrm{hpf}$ and in the temporal 
A

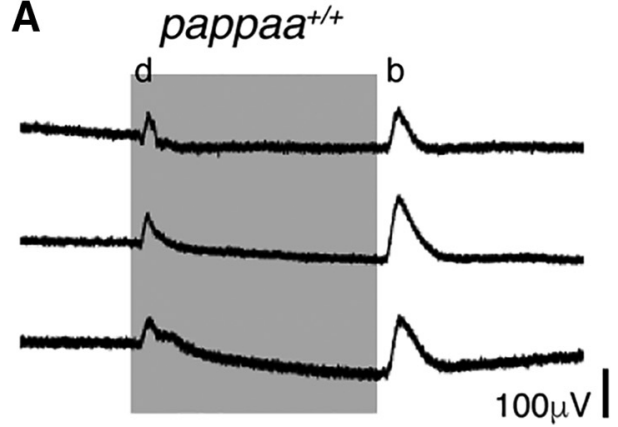

B

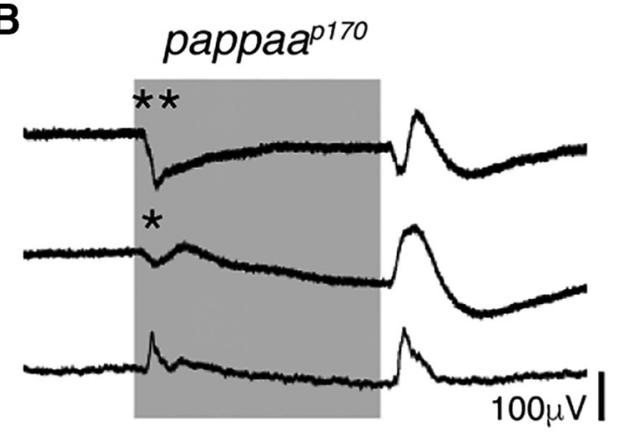

Figure 9. ERGs of wild-type and pappaa ${ }^{p 170}$ larvae. $\boldsymbol{A}, \boldsymbol{B}$, ERG recordings from $5 \mathrm{dpf}$ wild-type $(\boldsymbol{A})$ and pappaa ${ }^{p 170}$ larvae $(\boldsymbol{B})$ to $1 \mathrm{~s}$ light offset (gray region) and onset. Each trace is from a single larva and represents the mean change in amplitude from 20 recordings. All wild-type traces showed increased amplitudes at light offset ( $d$-wave) and onset (b-wave). For pappaa ${ }^{p 170}$ larvae, three representative traces are shown for the three outcomes observed for the $d$-wave: minimal d-wave $\left({ }^{*}\right)$, negative $d$-wave $\left({ }^{* *}\right)$, and a wild-type-like $d$-wave (bottom).

region of the retinal ganglion cell layer at $72 \mathrm{hpf}$ (Fig. $4 A, B$ ). Beginning at $72 \mathrm{hpf}$ and persisting through $120 \mathrm{hpf}$, pappaa was expressed in the retinal inner nuclear layer (INL) where Müller glia and bipolar cells' somas are located (Fig. $4 B, C$, bracketed). This INL expression did not colocalize with a marker of Müller glia (Fig. 4D). pappaa expression was not observed within the optic tecta between 72 and $120 \mathrm{hpf}$ (Fig. 4E,F), although pappaa expression was detected in the brain ventral and medial to the tecta. Thus, pappaa is expressed in the distal retinal INL when synapses form between cones and bipolar cells. At this time and consistent with IGF1R signaling mediating Pappaa-dependent responses to light offset (Fig. 3), we visualized activated IGF1R where cones and bipolar cells form synaptic connections in the OPL (Fig. 5A). Notably, we observed a reduction in anti-phosphorylated IGF1R (pIGF1R) immunolabeling in the OPL of pappaa $^{p 170}$ larvae (Fig. $5 B, C$ ). pIGF1R labeling of the IPL and in the tecta was similar in wild-type and pappaa ${ }^{p 170}$ larvae (Fig. $5 C$ ).

\section{pappaa $^{\text {p170 }}$ retinas have a disrupted OPL}

pappaa's earlier (36 hpf) retinal expression suggested that Pappaa loss of function could have widespread effects on retinal development that might disrupt intraretinal processing of light offset. To assess this possibility, we evaluated retinal lamination and gross cytoarchitecture by performing histology on wild-type and pappaa $^{p 170}$ retinas at 5 and $10 \mathrm{dpf}$. Consistent with the smaller size of pappaa ${ }^{p 170}$ larvae and growth-promoting role of PappaaIGF1 signaling (Conover et al., 2004; Wolman et al., 2015), the pappaa $^{p^{170}}$ retinas appeared slightly smaller in size. By H\&E staining, pappaa ${ }^{p 170}$ retinas showed overtly normal lamination (Fig. 6A, B, E, F) and the number of cells per area in each retinal layer of wild-type larvae was similar to that of pappaa ${ }^{p 170}$ larvae (Fig. 6J). To determine whether each layer consisted of the proper retinal cell types, we performed whole-mount immunolabeling with markers of cone and rod photoreceptors, bipolar cells, horizontal cells, amacrine cells, radial glia, retinal ganglion cells, and the retinotectal projection. All of these cell types were present in pappaa $^{p 170}$ retinas, in the proper layer, and with the same abundance as observed in wild-type retinas (Fig. $7 A-H^{\prime}$ ). The retinotectal projections appeared normal in pappaa ${ }^{p 170}$ larvae, as indicated by the anatomy of the projection (Fig. $7 \mathrm{H}, \mathrm{H}^{\prime}$ ) and the degree of tectal innervation at $5 \mathrm{dpf}$ [Fig. 7I, I'; isl2b-gfp fluorescent intensity, raw integrated density per area (units/ $\mu \mathrm{m}^{2}$ ) minus background: wild-type, 78,250.97 $\pm 6228.36, n=$ 10 samples, 1 tectum per sample; pappaa ${ }^{p 170}, 93,531.96 \pm$ 4294.35, $n=11$ samples, 1 tectum per sample; $p=0.06, t$ test $]$. A closer inspection of the $5 \mathrm{dpf}$ retinal histology revealed that the width of the pappaa ${ }^{p 170}$ larvae's OPL was reduced by $\sim 12.66 \%$ (Fig. 6C,D,I). At $10 \mathrm{dpf}$, the pappaa ${ }^{p 170}$ larvae's OPL appeared disorganized and the reduction in width was more pronounced (38.81\%; Fig. $6 G-I$ ), indicating the difference at $5 \mathrm{dpf}$ was not transient and that the phenotype progressively worsened. Notably, the width of the IPL was equivalent between genotypes at both stages (Fig. 6I).

A thin OPL has been associated with impaired photoreceptor synaptic development and visual function (Jia et al., 2014), and thus prompted an evaluation of synaptic markers in wild-type and pappaa ${ }^{p 170}$ retinas. We labeled $5 \mathrm{dpf}$ retinas with antibodies against postsynaptic scaffolding proteins that mark excitatory (anti-MAGUK) and inhibitory (anti-gephyrin) postsynaptic densities within both plexiform layers. In both genotypes, the OPL and IPL showed a similar degree of immunolabeling and the antigephyrin labeling marked clearly defined laminae within the IPL (Fig. 8A-D). Given the pappaa ${ }^{p 170}$ larvae's impaired responses to light offset, we next evaluated the expression of AMPA-type glutamate receptors on OFF-bipolar cells' dendrites, which mediate their activation by glutamate release from photoreceptors at light offset. The number of anti-AMPAR-labeled puncta per cone in the OPL in pappaa ${ }^{p 170}$ larval retinas was the same as that in wildtype larval retinas (Fig. $8 E, F$; wild type, $2.02 \pm 0.13, N=8$ samples, $\geq 15$ cones per sample; pappaa ${ }^{p 170}, 2.02 \pm 0.07, N=8$ samples, $\geq 14$ cones per sample; $p=0.99, t$ test). We next analyzed presynaptic vesicles in photoreceptors at the OPL by immunolabeling with anti-SV2. Although there was labeling in the OPL of both wild-type and pappaa ${ }^{p 170}$ larvae (Fig. $8 G, H$ ), we observed abundant irregularities in the anti-SV2 labeling in $75 \%$ of pappaa $^{p 170}$ larvae $(N=8)$, which were rarely observed in the OPL of wild-type retinas. These irregularities included gaps in antiSV2 labeling (Fig. $8 H$, arrowhead) and labeling that extended farther into the photoreceptor layer than observed in wild type (Fig. $8 H$, arrows).

\section{pappaa mutants exhibit reduced cone-to-OFF bipolar cell synaptic activity}

Cone photoreceptors modulate synaptic vesicle release within the OPL to activate parallel circuits that convey light onset versus offset (Fig. $1 A, B$ ). In response to light onset, cones hyperpolarize and reduce synaptic vesicle release to activate ON bipolar cells. In response to light offset, cones depolarize and increase synaptic vesicle release to activate OFF bipolar cells. Based on the pappaa ${ }^{p 170}$ larvae's behavioral defects being limited to light offset, we hypothesized that Pappaa activity is required for synaptic transmission between cones and OFF bipolar cells, but not between cones 
A

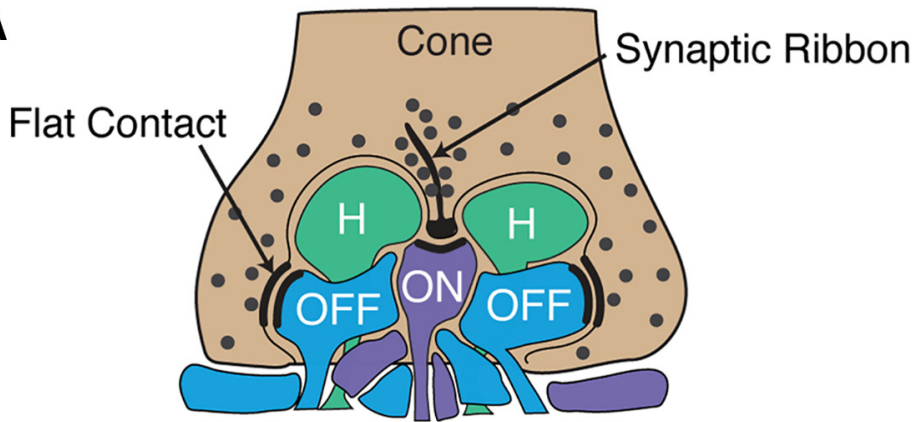

B

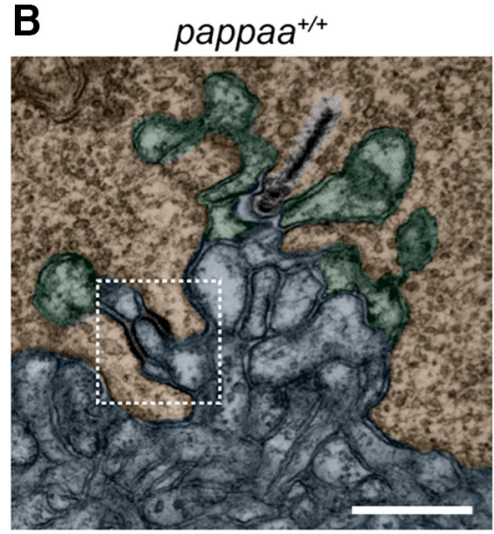

D

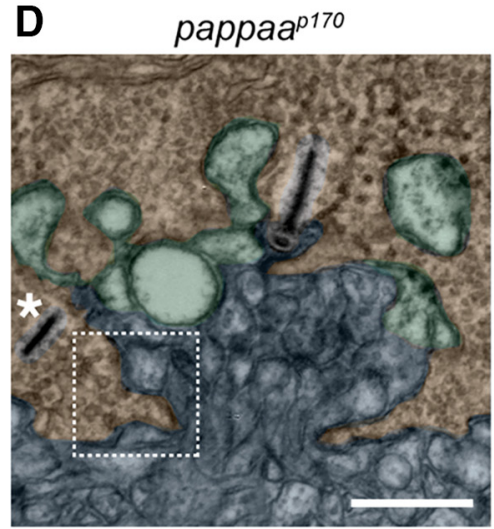

$\mathbf{F}$

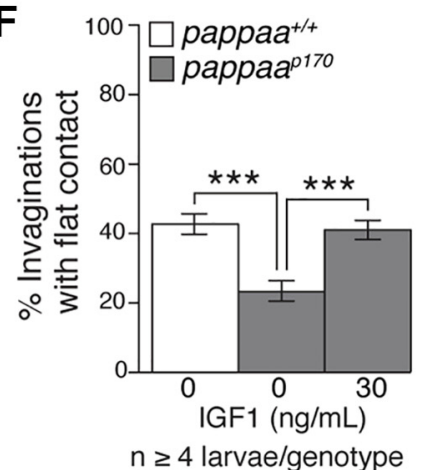

$\mathrm{n} \geq 4$ larvae/genotype

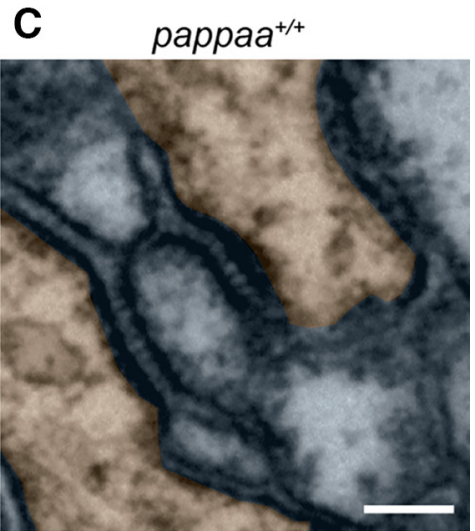

E

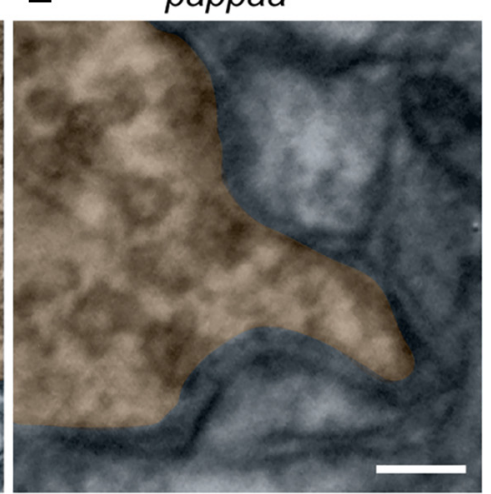

G

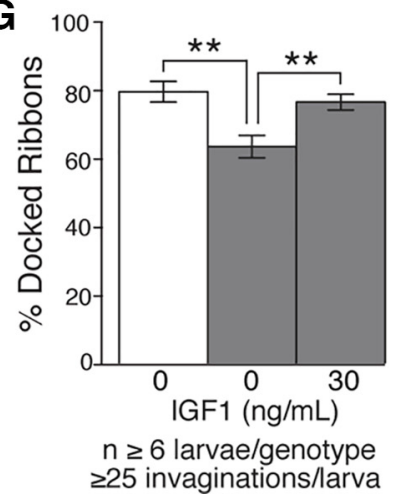

Figure 10. pappaa $^{p 170}$ larvae show reduced synaptic vesicle docking in retinal photoreceptors. $\boldsymbol{A}$, Schematic of photoreceptor synaptic terminal with dendrites of ON (purple) and OFF (blue) bipolar cells and horizontal ( $\mathrm{H}$, green) cells forming invaginations into the cone synaptic terminal. $\boldsymbol{B}-\boldsymbol{E}$, EMs of cone terminals in wild-type $(\boldsymbol{B}, \boldsymbol{C})$ and pappaa ${ }^{\text {p170 }}$ larvae $(\boldsymbol{D}, \boldsymbol{E})$. Coloring matches diagram in $\boldsymbol{A}$, except all bipolar cell dendrites are blue-gray. $\boldsymbol{C}, \boldsymbol{E}$, Higher magnification of boxed regions in $\boldsymbol{B}$ and $\boldsymbol{D}$ to highlight flat contact. Asterisk in $\boldsymbol{D}$ marks undocked, "floating" synaptic ribbons. Scale bars: $\boldsymbol{B}, \boldsymbol{D}, 500 \mathrm{~nm} ; \boldsymbol{C}, \boldsymbol{E}, 100 \mathrm{~nm}$. $\boldsymbol{F}$, Mean percentage of invaginations with an identifiable flat contact, as indicated by a presynaptic electron-dense region found laterally within an invagination and across the synaptic cleft from a postsynaptic electron-dense band. $\mathbf{G}$, Mean percentage of ribbons that were docked, as defined by proximity to cone's presynaptic membrane and presence of archiform density. ${ }^{* *} p<0.01,{ }^{* * *} p<0.001$, one-way ANOVA. N indicated under graphs. Error bars indicate SEM.

and ON bipolar cells. To measure outer retina synaptic function in response to both light offset and onset, we performed ERGs in immobilized larvae that were light-adapted and then exposed to a series of $1 \mathrm{~s}$ dark flashes. ERGs record neuronal field potential changes specific to $\mathrm{ON}$ or OFF bipolar cells following changes in luminance (Wong et al., 2004). Upon light offset, $100 \%$ of ERG recordings from wild-type larvae ( $n=6$ larvae, 20 stimuli per larva) showed an expected increase in amplitude (d-wave; Fig. 9), which indicated functional synapses between cones and OFF bipolar cells. In contrast, ERG recordings from only $58 \%$ of pappaa ${ }^{p 170}$ larvae ( $n=12$ larvae, 20 stimuli per larva) showed a typical d-wave. At light offset, the ERGs from 3 of 12 larvae had minimal amplitude change (Fig. 9B, single asterisk) and 2 of 12 larvae exhibited an inverted waveform (Fig. 9B, double asterisk). In response to the light onset that followed each $1 \mathrm{~s}$ dark flash, ERG recordings from $100 \%$ of the wild-type and pappaa ${ }^{p 170}$ larvae exhibited the expected robust increase in amplitude (b-wave; Fig. 9), which is indicative of functional cone phototransduction and synaptic transmission between cones and ON bipolar cells. These results suggest that $p a p p a a^{p 170}$ larvae have functionally normal cone-to-ON bipolar cell synapses, but have deficient synaptic activity between cones and OFF bipolar cells.

\section{Pappaa-IGF1 signaling regulates presynaptic architecture of cone photoreceptors}

We next evaluated the ultrastructural integrity of the OPL by performing EM on 5 dpf wild-type and pappaa ${ }^{p 170}$ retinas. Invaginations into the photoreceptor layer by bipolar and horizontal cell dendrites clearly marked regions within the OPL where cone photoreceptors formed synapses with these second-order neurons (Fig. 10A). By comparing EM micrographs of wild-type retinas with micrographs of pappaa ${ }^{p 170}$ retinas, we observed a similar number of invaginations per 100 $\mu \mathrm{m}$ along the anterior-posterior axis of the OPL (wild type, $15.47 \pm 0.84, n=5$ larvae; pappaa ${ }^{\text {p170 }}, 14.53 \pm 0.94, n=5$ larvae; $p=0.53, t$ test). These invaginations were of the same size (invagination area: wild type, $1.34 \pm 0.06 \mu \mathrm{m}^{2}, n=5$ larvae averaged from 10 invaginations per larva; pappaa ${ }^{p 170}, 1.24 \pm 0.09 \mu \mathrm{m}^{2}$, $n=5$ larvae averaged from 10 invaginations per larva; $p=0.44, t$ test). The invaginations consisted of an equal abundance of horizontal and bipolar cell 
dendrites (Fig. 10B,D). Wild-type and pappaa $^{\text {p170 }}$ cones possessed approximately the same number of synaptic vesicles within $150 \mathrm{~nm}$ of the cone presynaptic membrane (vesicles per area: wild type, $126.40 \pm 4.02 \mu \mathrm{m}^{2}, n=4$ larvae, averaged from 3 invaginations per larva; pap$p^{p a a^{p 170}}, 122.78 \pm 5.34 \mu \mathrm{m}^{2}, n=4$ larvae averaged from 3 invaginations per larva; $p=0.82$, $t$ test). Next, we evaluated the cone presynaptic domains positionally coupled to ON and OFF bipolar cell dendrites. Flat contacts between cones and OFF bipolar cell dendrites were identified based on the apposed, electron-rich presynaptic and postsynaptic densities within the peripheral regions of the invaginations (Fig. 10A-C; Dowling and Boycott, 1966; Nelson and Connaughton, 1995). In pap$p a a^{p 170}$ larvae, we observed a striking $47.62 \%$ reduction in the number of invaginations with an identifiable flat contact (Fig. 10D-F). At contacts with $\mathrm{ON}$ bipolar cells, synaptic ribbons were highly visible, docked to the presynaptic cone membrane, and anchored by an archiform density. In pappaa ${ }^{p 170}$ cones we observed an increase in the presence of "floating," undocked ribbons that lacked an archiform density (Fig. 10G, asterisk). Thus, the percentage of docked ribbons was mildly reduced in pappaa ${ }^{p^{170}}$ larvae (Fig. $10 G)$. To determine whether Pappaa acts via IGF1 signaling to promote the integrity of these structures, we asked whether stimulation of IGF1 signaling in pappaa ${ }^{p 170}$ larvae would restore these structures as it did for light-offset responses. Indeed, exposure of pap$p a a^{p 170}$ larvae to IGF1 from 3 to $5 \mathrm{dpf}$ increased the percentage of invaginations with an identifiable flat contact and docked synaptic ribbons to wild-type levels (Fig. $10 F, G$ ).

The physiological role and structural makeup of flat contacts remains unclear. These domains have been dismissed as sites of synaptic vesicle release based on failure to visualize nearby and/or docked synaptic vesicles. Notably, our EM images indicated synaptic vesicles near the flat contacts' presynaptic density (Fig. 11, arrowheads; mean synaptic vesicles within $200 \mathrm{~nm}, 4.92 \pm 1.20$, $N=12$ flat contacts from 4 wild-type retinas). Consistent with the idea that loss of flat contacts' presynaptic domain, and hence, reduced vesicle release, may underlie the pappaa ${ }^{p 170}$ larvae's defect in responding to light offset, we found that acute, $20 \mathrm{~min}$ treatment of the pappaa ${ }^{p 170}$ larvae with AMPA was sufficient to restore their initiation of light-offset responses (Fig. 12). Finally, we evaluated OFF bipolar cells' presynaptic terminals in the IPL, since their loss could contribute to the pappaa ${ }^{p 170}$ larvae's impaired responses to light offset. Quantification of synaptic ribbons in the IPL, and in particular the outer laminae of the IPL where OFF bipolar cells project (Nelson and Connaughton, 1995; Nevin et al., 2008), did not reveal a difference between wild-type and pappaa ${ }^{p 170}$ larvae (Fig. 13). Together, these results reveal a novel role for Pappaa-regulated IGF1R signaling in supporting cone presynaptic structures.

\section{Discussion}

Neural signals coding light onset and offset are split into parallel retinal circuits via discrete synapses between photoreceptors and distinct bipolar cells. Despite an understanding of these synapses' physiology, it remains poorly understood how molecular cues establish their architecture to mediate signal splitting, particu- larly to convey light offset. Here, we characterized a unique zebrafish mutant with visual impairment specific to light offset. This analysis revealed Pappaa as a novel molecular regulator of cone-to-OFF bipolar cell synaptic structure and function and describes Pappaa's first known role in synapse development.

\section{Pappaa regulates visual responses specific to light-offset stimuli}

The precise impact of Pappaa on retinal circuits is demonstrated by the specificity of the pappaa ${ }^{p 170}$ mutants' defects in visually guided behaviors and cone-to-bipolar cell synaptic structure and physiology. pappaa ${ }^{p 170}$ larvae failed to properly initiate behaviors to light offset (Figs. 1C, 2D), yet showed normal initiation of behaviors to light onset (Fig. $1 D$ ) and when facing a light stimulus (Fig. 2C). When pappaa ${ }^{p 170}$ larvae initiated behavior to light onset or offset, startled to sound, or moved spontaneously (Wolman et al., 2015), the kinematic parameters of their maneuvers were normal, indicating intact motor function. This analysis suggests Pappaa acts upstream of the visual circuit's motor component to regulate detection and/or interpretation of light offset. The significance of this role was further demonstrated by the pappaa ${ }^{p 170}$ larvae's diminished contrast-dependent behaviors, including the OKR (Fig. 2A), phototaxis navigation (Fig. $2 B, C$ ), and prey capture (A.H. Miller and M.A. Wolman, unpublished observations).

Multiple observations suggest that Pappaa acts in the outer retina to mediate light-offset detection and/or interpretation. Processing of light input occurs in the retina and the retina's projection targets in the brain, which is primarily the tectum in zebrafish. Within the timeframe of our analyses, pappaa was not expressed by the tecta, but was retinally expressed (Fig. 4). When IGF1 signaling was required for light-offset responses (Fig. 3DI), pappaa's retinal expression was largely restricted to the INL (Fig. $4 B, C$ ). This pappaa expression coincides with the position of Müller glia and bipolar cell somas but does not colocalize with Müller glia (Fig. 4D), suggesting that pappaa is expressed postsynaptically for cone-to-bipolar cell synapses. From ERGs recorded in pappaa $^{\text {p170 }}$ larvae, normal cone-to-ON bipolar cell waveforms indicated these synapses were functional and cone phototransduction was intact (Fig. 9). The aberrant waveforms at light offset revealed dysfunction specific to the cone-to-OFF bipolar cell synapses (Fig. 9B). Notably, the ERG revealed a milder defect in pappaa $^{\text {p170 }}$ larvae compared with their more robust behavioral 
A

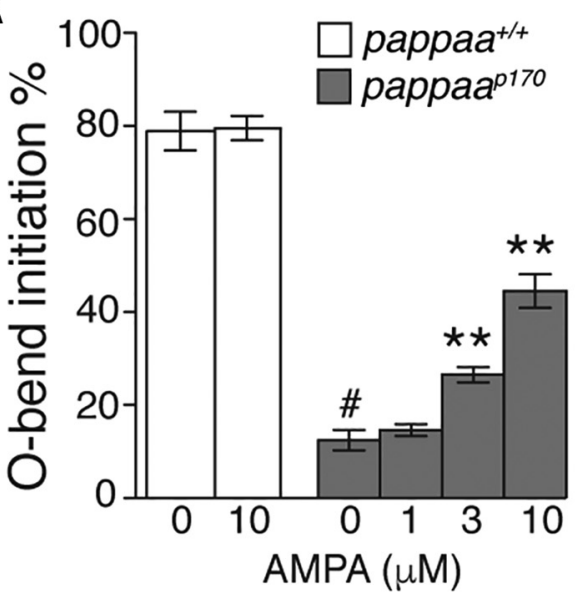

B

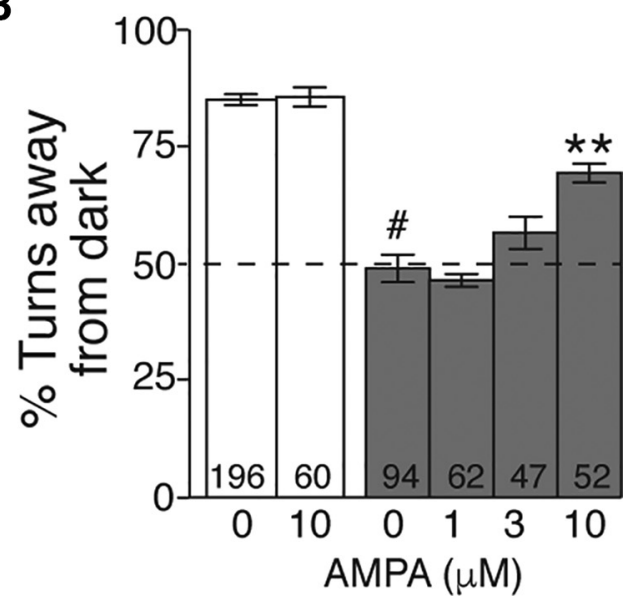

Figure 12. AMPA supplementation improves 0 -bend responsiveness in pappaa ${ }^{p 170}$ larvae. $\boldsymbol{A}, \boldsymbol{B}$, Larvae were treated for 30 min before and during exposure to 10 dark flashes ( $\boldsymbol{A}$ ) or phototaxis assay $(\boldsymbol{B})$ at $5 \mathrm{dpf}$. $\boldsymbol{A}$, Mean initiation frequency of 0 -bend responses. $N=5$ groups of 15 larvae per treatment group. $\boldsymbol{B}$, Mean percentage of turns initiated away from darkness by larvae positioned between 75 and $105^{\circ}$ to the light-dark gradient. $N$ at base of bars, Number of trials in which a turn was evaluated based on larval position with respect to target light. \#p $<0.001$ versus untreated wild-type larvae and ${ }^{* *} p<0.01$ versus untreated pappaa ${ }^{p 170}$ larvae, ANOVA with Bonferroni's correction.

A

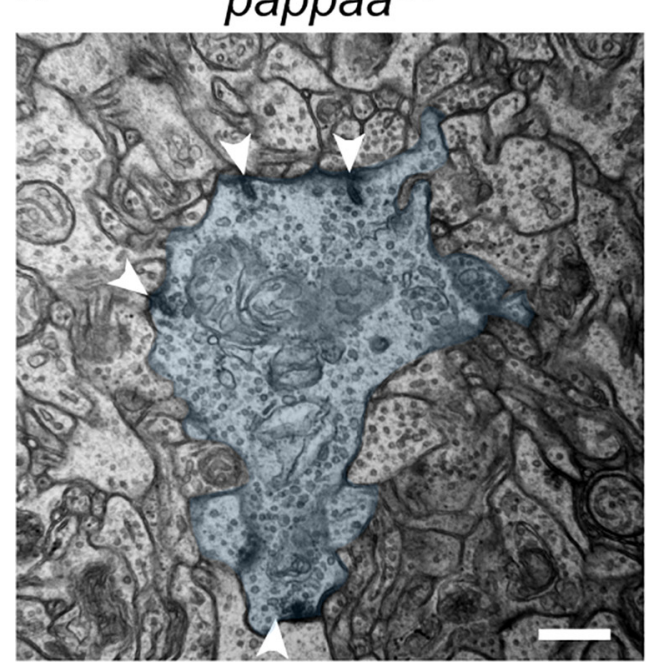

C
B

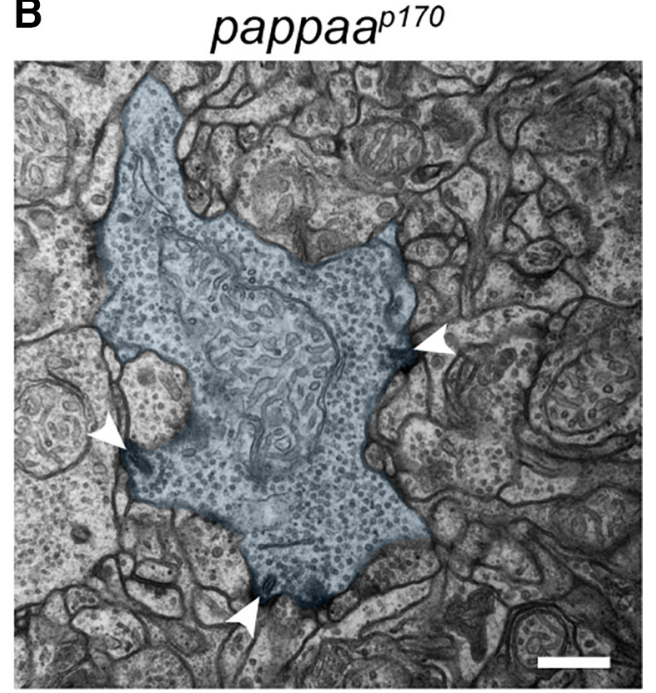

$\square$ pappaa $^{+/+}$

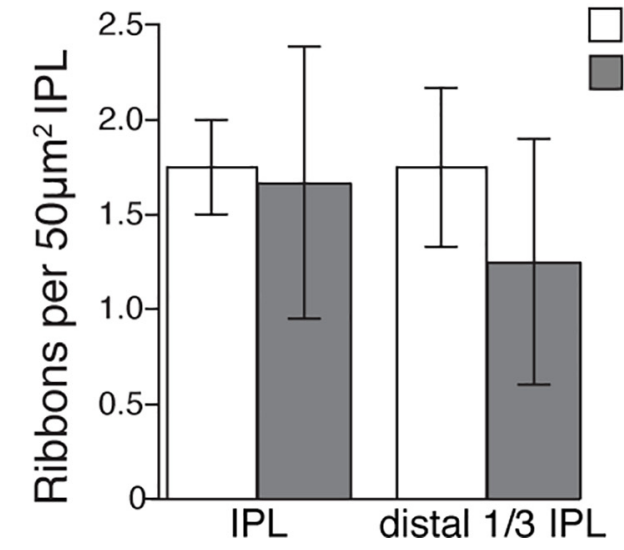

Figure 13. OFF bipolar cell synaptic ribbons in the IPL. $\boldsymbol{A}, \boldsymbol{B}$, EMs of IPL synapses in wild-type $(\boldsymbol{A})$ and pappap ${ }^{p 170}(\boldsymbol{B})$ larvae. OFF bipolar cell terminals (shaded in blue-gray) identified by location in the distal third of the IPL and presence of synaptic ribbons (white arrowheads). Scale bars, $500 \mathrm{~nm}$. C, Mean number of synaptic ribbons per area of IPL. $n=4$ larvae per genotype. Error bars indicate SEM.

deficit. This discrepancy could be due to the ERG being a less sensitive assay for assessing light-offset responses and/or to differences in how the larvae are tested by ERG and for behavior (ERG: immobilized, anesthetized; behavior: free swimming) and/or the light stimuli used. Additionally, pappaa ${ }^{p 170}$ larvae may harbor circuit defects downstream of the cone-to-OFF bipolar cell synapses, which would be undetectable by ERG, but could further disrupt transmission of the light-offset neural signals. We 
failed to identify such a defect through our histological, ultrastructural, and immunohistochemical analyses. Rather, the structural defects we identified were limited to the cone presynaptic terminals.

\section{Pappaa regulates cone presynaptic structure}

To understand how Pappaa promotes light-offset responses, it is important to consider where Pappaa influences retinal circuitry. pappaa's INL expression (Fig. 4B-D) combined with the pappaap170 larvae's ERG (Fig. 9B), retinal histology (Fig. 6), and IGF1R phosphorylation (Fig. 5), suggest that Pappaa influences circuits within the OPL. Here, the synaptic configuration between the photoreceptors and bipolar cells splits inputs of light onset and offset. At light offset, transient glutamate release from cones activates AMPARs on OFF bipolar cell dendrites to transmit a message of light offset to ganglion cells (Wässle, 2004). Thus, impairment in initiating light-offset responses could be caused by a structural and/or functional defect at either the cone-to-OFF bipolar synapses or by the OFF bipolar cells' innervation of the IPL. Here we show evidence suggesting Pappaa does not mediate OFF bipolar cell structure or function within the timeframe of our analyses. First, the number and size of dendritic invaginations into cone terminals were normal in pappaa ${ }^{p 170}$ larvae. Second, AMPARs, expressed by horizontal and OFF bipolar cell dendrites, showed normal expression in pappaa ${ }^{p 170}$ larvae. Third, OFF bipolar cells in pap$p_{a a^{p 170}}$ mutant retinas exhibit normal synaptic ribbons in their synaptic terminals in the IPL (Fig. 13). Finally, pappaa ${ }^{p 170}$ larvae showed improved responses to light-offset stimuli when acutely treated with AMPA (Fig. 12), suggesting their OFF bipolar cells were competent. Together, these results suggest the circuit defect underlying the pappaa ${ }^{p 170}$ larvae's deficient light-offset response is unlikely to be localized to OFF bipolar cells.

The pappaa ${ }^{p 170}$ cones' reduced flat contact presynaptic domains and mislocalized synaptic ribbons provide evidence that the circuit defect underlying the impaired light-offset responses is in the cones' presynaptic terminal. Although ribbons mediate glutamate release at light offset, mutant analyses have demonstrated the cones' ribbons are dispensable for light-offset responses in larval zebrafish (Allwardt et al., 2001; Emran et al., 2008). Photoreceptors have nonribbon-mediated sites of glutamate release (Chen et al., 2013), but the presynaptic domains of flat contacts have been dismissed as a release site based on descriptions, including in zebrafish, that claim this region is devoid of synaptic vesicles (Dowling and Boycott, 1966; Haverkamp et al., 2000; Allwardt et al., 2001; DeVries et al., 2006). Our EMs rebut this claim by showing vesicle-like structures near and apparently docked at the flat contacts' presynaptic membrane (Fig. 11). Though the presynaptic density was less at the flat contacts than at the ribbons, that density may be sufficient because glutamate from a just a single vesicle is enough to depolarize an OFF bipolar cell (DeVries et al., 2006). Glutamate release at the flat contact is positionally more favorable to activate AMPARs on OFF bipolar cell dendrites compared with the ribbon-mediated glutamate release that occurs hundreds of nanometers away. The possibility that the pappaa $^{p 170}$ mutant has uncovered a novel role for the flat contacts in mediating vesicular glutamate release is exciting. However, direct evidence of synaptic vesicle release at this locus is needed to confirm this. To understand Pappaa's relationship with flat contacts and this locus's potential role in glutamate release and lightoffset responses, it will also be critical to characterize the structural composition of the flat contacts' presynaptic domain, which remains a mystery (Boycott and Hopkins, 1993; Tsukamoto and Omi, 2015).

\section{Pappaa regulates IGF1R signaling to promote light-offset responses and synaptic structure}

Presynaptic domains develop through the signaling of molecular cues, which may be expressed and act within the presynaptic neuron, postsynaptic neuron, or surrounding cells (Cohen-Cory, 2002; Shen and Cowan, 2010). IGF1 regulates circuit development and function by binding the IGF1R, which activates intracellular signaling cascades, including the PI3K-Akt-mTOR pathway (Dyer et al., 2016; Nieto-Estévez et al., 2016). For cone-to-bipolar cell synapses, our data suggest pappaa is expressed postsynaptically (Fig. $4 B-D)$ and stimulates local IGF1R signaling during cone synapse development to establish flat contacts and mediate light-offset responses (Figs. 3, 5, 10F). Retinal IGF1 may arise from a number of sources, including retinal neurons (Mack et al., 1995; Burren et al., 1996), retinal pigment epithelium (Waldbillig et al., 1991; Holtkamp et al., 2001), or the liver (Pan and Kastin, 2000; Daftary and Gore, 2005). Activation of IGF1Rs promotes synapse formation and function through presynaptic and postsynaptic mechanisms (Torres-Aleman, 1999; Dyer et al., 2016; Nieto-Estévez et al., 2016). Given the IGF1R's widespread neural expression during development, locally acting regulators of IGF1 signaling, like Pappaa, must be important for mediating specific aspects of circuit formation and function.

Evidence presented here suggests Pappaa-IGF1 signaling influences cone presynaptic domains at synapses with OFF bipolar cells. However, it remains unclear which outer retinal cell types require IGF1R activity to establish these domains. Pappaa could act in an autocrine manner to stimulate postsynaptic IGF1R signaling in OFF bipolar cells. Postsynaptically, IGF1 has been shown to promote dendritic growth (Camarero et al., 2001; Cheng et al., 2003; Shi et al., 2005; Carlson et al., 2014), membrane receptor and channel stability through the activity of synaptic scaffolding proteins (Corvin et al., 2012; Della Sala et al., 2016), and the development and maintenance of synaptic connections via cell adhesion molecules (Bonfanti, 2006; Monzo et al., 2013). Although we did not observe defects in dendritic size (Fig. 10B,D) or abundance of AMPAR or postsynaptic density markers in the OPL of pappaa ${ }^{p 170} \mathrm{mu}-$ tants (Fig. 8), IGF1 signaling may act through other postsynaptic mechanisms to promote the development or maintenance of cone-OFF bipolar cell synaptic contacts. Alternatively, Pappaa may act in a paracrine manner to enhance IGF1R signaling in cones or another local cell type (e.g., horizontal cells or the still quiescent rods). Pappaa may free IGF1 to stimulate presynaptic, cone photoreceptor-dependent cellular mechanisms. IGF1 signaling has been shown to regulate axon guidance (Laurino et al., 2005; Scolnick et al., 2008), neurotransmitter release (Itakura et al., 2005), and voltage-dependent calcium-channel currents (Blair and Marshall, 1997; Blair et al., 1999; Xing et al., 2006). Any of these processes could affect cone-OFF bipolar cell synaptic structure and function. An extensive series of cell-specific Pappaa and IGF1R manipulations will be required to distinguish the autocrine/paracrine nature of Pappaa-IGF1 signaling and how it influences cone-to-OFF bipolar cell synapse formation.

\section{References}

Allwardt BA, Lall AB, Brockerhoff SE, Dowling JE (2001) Synapse formation is arrested in retinal photoreceptors of the zebrafish nrc mutant. J Neurosci 21:2330-2342. CrossRef Medline

Biehlmaier O, Neuhauss SC, Kohler K (2003) Synaptic plasticity and functionality at the cone terminal of the developing zebrafish retina. J Neurobiol 56:222-236. CrossRef Medline

Blair LA, Marshall J (1997) IGF-1 modulates N and L calcium channels in a PI 3-kinase-dependent manner. Neuron 19:421-429. CrossRef Medline Blair LA, Bence-Hanulec KK, Mehta S, Franke T, Kaplan D, Marshall J 
(1999) Akt-dependent potentiation of L channels by insulin-like growth factor-1 is required for neuronal survival. J Neurosci 19:1940-1951. CrossRef Medline

Boldt HB, Overgaard MT, Laursen LS, Weyer K, Sottrup-Jensen L, Oxvig C (2001) Mutational analysis of the proteolytic domain of pregnancyassociated plasma protein-A (PAPP-A): classification as a metzincin. Biochem J 358:359-367. CrossRef Medline

Bonfanti L (2006) PSA-NCAM in mammalian structural plasticity and neurogenesis. Prog Neurobiol 80:129-164. CrossRef Medline

Boycott BB, Hopkins JM (1993) Cone synapses of a flat diffuse cone bipolar cell in the primate retina. J Neurocytol 22:765-778. CrossRef Medline

Brockerhoff SE, Hurley JB, Janssen-Bienhold U, Neuhauss SC, Driever W, Dowling JE (1995) A behavioral screen for isolating zebrafish mutants with visual system defects. Proc Natl Acad Sci U S A 92:10545-10549. CrossRef Medline

Burgess HA, Granato M (2007a) Sensorimotor gating in larval zebrafish. J Neurosci 27:4984-4994. CrossRef Medline

Burgess HA, Granato M (2007b) Modulation of locomotor activity in larval zebrafish during light adaptation. J Exp Biol 210:2526-2539. CrossRef Medline

Burgess HA, Schoch H, Granato M (2010) Distinct retinal pathways drive spatial orientation behaviors in zebrafish navigation. Curr Biol 20:381386. CrossRef Medline

Burren CP, Berka JL, Edmondson SR, Werther GA, Batch JA (1996) Localization of mRNAs for insulin-like growth factor-I (IGF-I), IGF-I receptor, and IGF binding proteins in rat eye. Invest Ophthalmol Vis Sci 37:14591468. Medline

Camarero G, Avendano C, Fernandez-Moreno C, Villar A, Contreras J, de Pablo F, Pichel JG, Varela-Nieto I (2001) Delayed inner ear maturation and neuronal loss in postnatal igf-1-deficient mice. J Neurosci 21:76307641. CrossRef Medline

Carlson SW, Madathil SK, Sama DM, Gao X, Chen J, Saatman KE (2014) Conditional overexpression of insulin-like growth factor-1 enhances hippocampal neurogenesis and restores immature neuron dendritic processes after traumatic brain injury. J Neuropathol Exp Neurol 73:734-746. CrossRef Medline

Chablais F, Jazwinska A (2010) IGF signaling between blastema and wound epidermis is required for fin regeneration. Development 137:871-879. CrossRef Medline

Chalasani SH, Sabol A, Xu H, Gyda MA, Rasband K, Granato M, Chien CB, Raper JA (2007a) Stromal cell-derived factor-1 antagonizes slit/robo signaling in vivo. J Neurosci 27:973-980. CrossRef Medline

Chalasani SH, Chronis N, Tsunozaki M, Gray JM, Ramot D, Goodman MB, Bargmann CI (2007b) Dissecting a circuit for olfactory behaviour in Caenorhabditis elegans. Nature 450:63-70. CrossRef Medline

Chen M, Van Hook MJ, Zenisek D, Thoreson WB (2013) Properties of ribbon and non-ribbon release from rod photoreceptors revealed by visualizing individual synaptic vesicles. J Neurosci 33:2071-2086. CrossRef Medline

Cheng CM, Mervis RF, Niu SL, Salem N Jr, Witters LA, Tseng V, Reinhardt R, Bondy CA (2003) Insulin-like growth factor 1 is essential for normal dendritic growth. J Neurosci Res 73:1-9. CrossRef Medline

Cohen-Cory S (2002) The developing synapse: construction and modulation of synaptic structures and circuits. Science 298:770-776. CrossRef Medline

Conover CA (2012) Key questions and answers about pregnancy-associated plasma protein-A. Trends Endocrinol Metab 23:242-249. CrossRef Medline

Conover CA, Bale LK, Overgaard MT, Johnstone EW, Laursen UH, Füchtbauer EM, Oxvig C, van Deursen J (2004) Metalloproteinase pregnancy-associated plasma protein $\mathrm{A}$ is a critical growth regulatory factor during fetal development. Development 131:1187-1194. CrossRef Medline

Corvin AP, Molinos I, Little G, Donohoe G, Gill M, Morris DW, Tropea D (2012) Insulin-like growth factor 1 (IGF1) and its active peptide (1-3) IGF1 enhance the expression of synaptic markers in neuronal circuits through different cellular mechanisms. Neurosci Lett 520:51-56. CrossRef Medline

Daftary SS, Gore AC (2005) IGF-1 in the brain as a regulator of reproductive neuroendocrine function. Exp Biol Med (Maywood) 230:292-306. CrossRef Medline

Daniele LL, Emran F, Lobo GP, Gaivin RJ, Perkins BD (2016) Mutation of wrb, a component of the guided entry of tail-anchored protein pathway, disrupts photoreceptor synapse structure and function. Invest Ophthalmol Vis Sci 57:2942-2954. CrossRef Medline

Della Sala G, Putignano E, Chelini G, Melani R, Calcagno E, Michele Ratto G, Amendola E, Gross CT, Giustetto M, Pizzorusso T (2016) Dendritic spine instability in a mouse model of CDKL 5 disorder is rescued by insulinlike growth factor 1. Biol Psychiatry 80:302-311. CrossRef Medline

DeVries SH, Li W, Saszik S (2006) Parallel processing in two transmitter microenvironments at the cone photoreceptor synapse. Neuron 50:735748. CrossRef Medline

Dowling JE, Boycott BB (1966) Organization of the primate retina: electron microscopy. Proc R Soc Lond B Biol Sci 166:80-111. CrossRef Medline

Dyer AH, Vahdatpour C, Sanfeliu A, Tropea D (2016) The role of insulinlike growth factor 1 (IGF-1) in brain development, maturation and neuroplasticity. Neuroscience 325:89-99. CrossRef Medline

Easter SS Jr, Nicola GN (1996) The development of vision in the zebrafish (Danio rerio). Dev Biol 180:646-663. CrossRef Medline

Emran F, Rihel J, Dowling JE (2008) A behavioral assay to measure responsiveness of zebrafish to changes in light intensities. J Vis Exp pii:923. CrossRef Medline

Fadool JM, Dowling JE (2008) Zebrafish: a model system for the study of eye genetics. Prog Retin Eye Res 27:89-110. CrossRef Medline

Fleisch VC, Neuhauss SC (2006) Visual behavior in zebrafish. Zebrafish 3:191-201. CrossRef Medline

Gallio M, Ofstad TA, Macpherson LJ, Wang JW, Zuker CS (2011) The coding of temperature in the Drosophila brain. Cell 144:614-624. CrossRef Medline

Gjorgjieva J, Sompolinsky H, Meister M (2014) Benefits of pathway splitting in sensory coding. J Neurosci 34:12127-12144. CrossRef Medline

Gudikote JP, Imam JS, Garcia RF, Wilkinson MF (2005) RNA splicing promotes translation and RNA surveillance. Nat Struct Mol Biol 12:801-809. CrossRef Medline

Halloran MC, Severance SM, Yee CS, Gemza DL, Raper JA, Kuwada JY (1999) Analysis of a zebrafish semaphorin reveals potential functions in vivo. Dev Dyn 214:13-25. CrossRef Medline

Haverkamp S, Grünert U, Wässle H (2000) The cone pedicle, a complex synapse in the retina. Neuron 27:85-95. CrossRef Medline

Holtkamp GM, Kijlstra A, Peek R, de Vos AF (2001) Retinal pigment epithelium-immune system interactions: cytokine production and cytokineinduced changes. Prog Retin Eye Res 20:29-48. CrossRef Medline

Hoon M, Okawa H, Della Santina L, Wong RO (2014) Functional architecture of the retina: development and disease. Prog Retin Eye Res 42:44-84. CrossRef Medline

Itakura M, Yamamori S, Kuwahara R, Sekiguchi M, Takahashi M (2005) Two distinct regulatory mechanisms of neurotransmitter release by phosphatidylinositol 3-kinase. J Neurochem 94:502-509. CrossRef Medline

Jia S, Muto A, Orisme W, Henson HE, Parupalli C, Ju B, Baier H, Taylor MR (2014) Zebrafish Cacnalfa is required for cone photoreceptor function and synaptic ribbon formation. Hum Mol Genet 23:2981-2994. CrossRef Medline

Jo H, Mondal S, Tan D, Nagata E, Takizawa S, Sharma AK, Hou Q, Shanmugasundaram K, Prasad A, Tung JK, Tejeda AO, Man H, Rigby AC, Luo HR (2012) Small molecule-induced cytosolic activation of protein kinase akt rescues ischemia-elicited neuronal death. Proc Natl Acad Sci U S A 109: 10581-10586. CrossRef Medline

Kamei H, Ding Y, Kajimura S, Wells M, Chiang P, Duan C (2011) Role of IGF signaling in catch-up growth and accelerated temporal development in zebrafish embryos in response to oxygen availability. Development 138:777-786. CrossRef Medline

Kay JN, Chu MW, Sanes JR (2012) MEGF10 and MEGF11 mediate homotypic interactions required for mosaic spacing of retinal neurons. Nature 483:465-469. CrossRef Medline

Laurino L, Wang XX, de la Houssaye BA, Sosa L, Dupraz S, Cáceres A, Pfenninger KH, Quiroga S (2005) PI3K activation by IGF-1 is essential for the regulation of membrane expansion at the nerve growth cone. J Cell Sci 118:3653-3662. CrossRef Medline

Laviola L, Natalicchio A, Giorgino F (2007) The IGF-I signaling pathway. Curr Pharm Des 13:663-669. CrossRef Medline

Lawrence JB, Oxvig C, Overgaard MT, Sottrup-Jensen L, Gleich GJ, Hays LG, Yates JR 3rd, Conover CA (1999) The insulin-like growth factor (IGF)dependent IGF binding protein-4 protease secreted by human fibroblasts is pregnancy-associated plasma protein-A. Proc Natl Acad Sci U S A 96: 3149-3153. CrossRef Medline 
Lessieur EM, Fogerty J, Gaivin RJ, Song P, Perkins BD (2017) The ciliopathy gene ahil is required for zebrafish cone photoreceptor outer segment morphogenesis and survival. Invest Ophthalmol Vis Sci 58:448-460. CrossRef Medline

Lewis A, Wilson N, Stearns G, Johnson N, Nelson R, Brockerhoff SE (2011) Celsr3 is required for normal development of GABA circuits in the inner retina. PLoS Genet 7:e1002239. CrossRef Medline

Lin SY, Vollrath MA, Mangosing S, Shen J, Cardenas E, Corey DP (2016) The zebrafish pinball wizard gene encodes WRB, a tail-anchored-protein receptor essential for inner-ear hair cells and retinal photoreceptors. J Physiol 594:895-914. CrossRef Medline

Mack AF, Balt SL, Fernald RD (1995) Localization and expression of insulin-like growth factor in the teleost retina. Vis Neurosci 12:457-461. CrossRef Medline

Monzo HJ, Park TI, Dieriks BV, Jansson D, Faull RL, Dragunow M, Curtis MA (2013) Insulin and IGF1 modulate turnover of polysialylated neural cell adhesion molecule (PSA-NCAM) in a process involving specific extracellular matrix components. J Neurochem 126:758-770. CrossRef Medline

Nelson R, Connaughton V (1995) Bipolar cell pathways in the vertebrate retina. In: Webvision: the organization of the retina and visual system (Kolb H, Fernandez E, Nelson R, eds). Salt Lake City: University of Utah Health Sciences Center.

Neuhauss SC (2003) Behavioral genetic approaches to visual system development and function in zebrafish. J Neurobiol 54:148-160. CrossRef Medline

Neuhauss SC, Biehlmaier O, Seeliger MW, Das T, Kohler K, Harris WA, Baier H (1999) Genetic disorders of vision revealed by a behavioral screen of 400 essential loci in zebrafish. J Neurosci 19:8603-8615. CrossRef Medline

Nevin LM, Taylor MR, Baier H (2008) Hardwiring of fine synaptic layers in the zebrafish visual pathway. Neural Dev 3:36. CrossRef Medline

Nieto-Estévez V, Defterali Ç, Vicario-Abejón C (2016) IGF-I: a key growth factor that regulates neurogenesis and synaptogenesis from embryonic to adult stages of the brain. Front Neurosci 10:52. Medline

Oxvig C (2015) The role of PAPP-A in the IGF system: location, location, location. J Cell Commun Signal 9:177-187. CrossRef Medline

Pan W, Kastin AJ (2000) Interactions of IGF-1 with the blood-brain barrier in vivo and in situ. Neuroendocrinology 72:171-178. CrossRef Medline

Pereverzev AP, Gurskaya NG, Ermakova GV, Kudryavtseva EI, Markina NM, Kotlobay AA, Lukyanov SA, Zaraisky AG, Lukyanov KA (2015) Method for quantitative analysis of nonsense-mediated mRNA decay at the single cell level. Sci Rep 5:7729. CrossRef Medline

Portugues R, Engert F (2009) The neural basis of visual behaviors in the larval zebrafish. Curr Opin Neurobiol 19:644-647. CrossRef Medline

Schindelin J, Arganda-Carreras I, Frise E, Kaynig V, Longair M, Pietzsch T, Preibisch S, Rueden C, Saalfeld S, Schmid B, Tinevez JY, White DJ, Hartenstein V, Eliceiri K, Tomancak P, Cardona A (2012) Fiji: an opensource platform for biological-image analysis. Nat Methods 9:676-682. CrossRef Medline

Schmitz F (2014) Presynaptic $[\mathrm{Ca}(2+)]$ and GCAPs: aspects on the structure and function of photoreceptor ribbon synapses. Front Mol Neurosci 7:3. CrossRef Medline

Scholl B, Gao X, Wehr M (2010) Nonoverlapping sets of synapses drive on responses and off responses in auditory cortex. Neuron 65:412-421. CrossRef Medline
Scolnick JA, Cui K, Duggan CD, Xuan S, Yuan XB, Efstratiadis A, Ngai J (2008) Role of IGF signaling in olfactory sensory map formation and axon guidance. Neuron 57:847-857. CrossRef Medline

Shen K, Cowan CW (2010) Guidance molecules in synapse formation and plasticity. Cold Spring Harb Perspect Biol 2:a001842. CrossRef Medline

Shi L, Linville MC, Tucker EW, Sonntag WE, Brunso-Bechtold JK (2005) Differential effects of aging and insulin-like growth factor-1 on synapses in CA1 of rat hippocampus. Cereb Cortex 15:571-577. CrossRef Medline

Shi Y, Obert E, Rahman B, Rohrer B, Lobo GP (2017) The retinol binding protein receptor $2(\mathrm{Rbpr} 2)$ is required for photoreceptor outer segment morphogenesis and visual function in zebrafish. Sci Rep 7:16207. CrossRef Medline

Stearns G, Evangelista M, Fadool JM, Brockerhoff SE (2007) A mutation in the cone-specific $p d e 6$ gene causes rapid cone photoreceptor degeneration in zebrafish. J Neurosci 27:13866-13874. CrossRef Medline

Sullivan-Brown J, Bisher ME, Burdine RD (2011) Embedding, serial sectioning and staining of zebrafish embryos using JB-4 resin. Nat Protoc 6:46-55. CrossRef Medline

Torres-Aleman I (1999) Insulin-like growth factors as mediators of functional plasticity in the adult brain. Horm Metab Res 31:114-119. CrossRef Medline

Tsukamoto Y, Omi N (2015) OFF bipolar cells in macaque retina: typespecific connectivity in the outer and inner synaptic layers. Front Neuroanat 9:122. CrossRef Medline

Waldbillig RJ, Pfeffer BA, Schoen TJ, Adler AA, Shen-Orr Z, Scavo L, LeRoith D, Chader GJ (1991) Evidence for an insulin-like growth factor autocrineparacrine system in the retinal photoreceptor-pigment epithelial cell complex. J Neurochem 57:1522-1533. CrossRef Medline

Wang YX, Qian LX, Yu Z, Jiang Q, Dong YX, Liu XF, Yang XY, Zhong TP, Song HY (2005) Requirements of myocyte-specific enhancer factor $2 \mathrm{~A}$ in zebrafish cardiac contractility. FEBS Lett 579:4843-4850. CrossRef Medline

Wasfy MM, Matsui JI, Miller J, Dowling JE, Perkins BD (2014) Myosin $7 \mathrm{aa}(-/-)$ mutant zebrafish show mild photoreceptor degeneration and reduced electroretinographic responses. Exp Eye Res 122:65-76. CrossRef Medline

Wässle H (2004) Parallel processing in the mammalian retina. Nat Rev Neurosci 5:747-757. CrossRef Medline

Westheimer G (2007) The ON-OFF dichotomy in visual processing: from receptors to perception. Prog Retin Eye Res 26:636-648. CrossRef Medline

Wolman MA, Jain RA, Liss L, Granato M (2011) Chemical modulation of memory formation in larval zebrafish. Proc Natl Acad Sci U S A 108: 15468-15473. CrossRef Medline

Wolman MA, Jain RA, Marsden KC, Bell H, Skinner J, Hayer KE, Hogenesch JB, Granato M (2015) A genome-wide screen identifies PAPP-AAmediated IGFR signaling as a novel regulator of habituation learning. Neuron 85:1200-1211. CrossRef Medline

Wong KY, Gray J, Hayward CJ, Adolph AR, Dowling JE (2004) Glutamatergic mechanisms in the outer retina of larval zebrafish: analysis of electroretinogram b- and d-waves using a novel preparation. Zebrafish 1:121-131. CrossRef Medline

Xing C, Yin Y, He X, Xie Z (2006) Effects of insulin-like growth factor 1 on voltage-gated ion channels in cultured rat hippocampal neurons. Brain Res 1072:30-35. CrossRef Medline 